Florida International University FIU Digital Commons

6-6-2014

\title{
The Impact of Aphasia on Working Memory in Bilingual Adults
}

Giselle Ogrodnik

gogro001@fiu.edu

DOI: $10.25148 /$ etd.FI14071145

Follow this and additional works at: https://digitalcommons.fiu.edu/etd

\section{Recommended Citation}

Ogrodnik, Giselle, "The Impact of Aphasia on Working Memory in Bilingual Adults" (2014). FIU Electronic Theses and Dissertations. 1546.

https://digitalcommons.fiu.edu/etd/1546

This work is brought to you for free and open access by the University Graduate School at FIU Digital Commons. It has been accepted for inclusion in FIU Electronic Theses and Dissertations by an authorized administrator of FIU Digital Commons. For more information, please contact dcc@fiu.edu. 


\title{
FLORIDA INTERNATIONAL UNIVERSITY
}

\author{
Miami, Florida
}

THE IMPACT OF APHASIA ON WORKING MEMORY IN BILINUGAL ADULTS

A thesis submitted in partial fulfillment of the

requirements for the degree of

MASTER OF SCIENCE

in

SPEECH LANGUAGE PATHOLOGY

by

Giselle M. Ogrodnik

2014 
To: Dean Ora L. Strickland

College of Nursing and Health Sciences

This thesis, written by Giselle M. Ogrodnik, and entitled The Impact of Aphasia on Working Memory in Bilingual Adults, having been approved in respect to style and intellectual content, is referred to you for judgment.

We have read this thesis and recommend that it be approved.

Alfredo Ardila, Major Professor

Elaine Ramos, Major Professor

Monica Hough, Major Professor

Date of Defense: June 6th, 2014

The thesis of Giselle M. Ogrodnik is approved.

Dean Ora L. Strickland

Nicole Wertheim College of Nursing and Health Sciences

Dean Lakshmi N. Reddi
University Graduate School

Florida International University, 2014 
(C) Copyright 2014 by Giselle Ogrodnik

All rights reserved. 


\section{DEDICATION}

This work is dedicated to my loving parents and fiancé. Without your love and support none of this would be possible. I am forever grateful to you all.

With love,

Giselle 


\section{ACKNOWLEDGMENTS}

I would like to extend a special thank you to all of the skilled nursing facilities, assisted living facilities, and rehabilitation centers that have provided the utmost support, knowledge, and most importantly, access to their beloved patients. Your generosity will be forever appreciated. 


\section{ABSTRACT OF THE THESIS \\ THE IMPACT OF APHASIA ON WORKING MEMORY IN BILINGUAL ADULTS \\ by}

Giselle M. Ogrodnik

Florida International University, 2014

Miami, Florida

Professor Monica Hough, Major Professor

The purpose of this investigation was to explore the effects of aphasia on working memory (WM) in bilingual adults. The relationship between WM capacity and auditory comprehension, as measured by the Token Test, was investigated in bilingual adults with and without aphasia. Additional areas of investigation included examination of the influence of aphasia on bilingualism and language proficiency as measured by differential performance in both languages on the Boston Naming Test; relationships between severity of aphasia, as measured by the Bilingual Aphasia Test; and WM, measured by listening span.

Sixteen participants between the ages of 26 and 91 were included in this study (mean age for women was 61.3; men was 52.8). Eight participants were non-aphasic bilingual adults, the remaining 8 participants were bilingual aphasic adults. Results suggest that the impact of bilingualism on WM for aphasic adults may be similar to what has been observed for monolingual aphasic individuals. 


\section{TABLE OF CONTENTS}

CHAPTER

PAGE

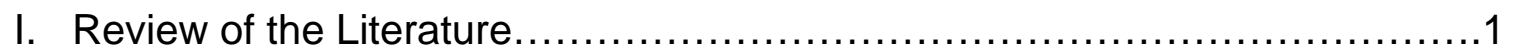

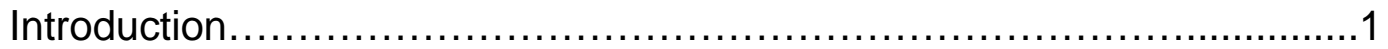

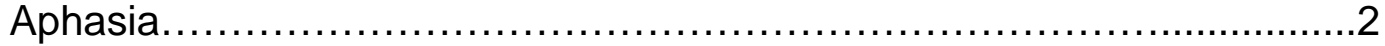

Language Processing in Aphasia ..........................................

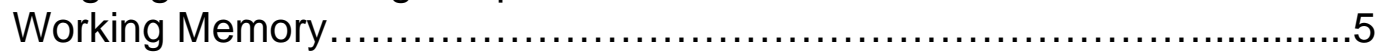

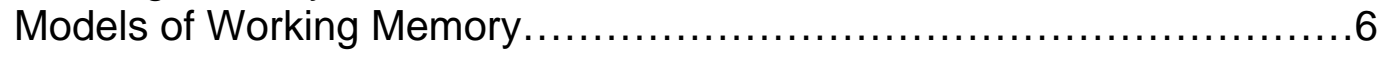

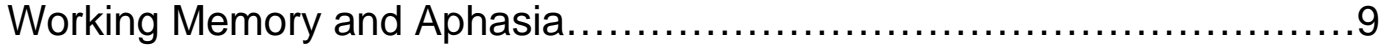

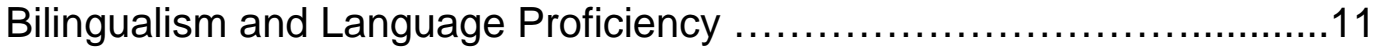

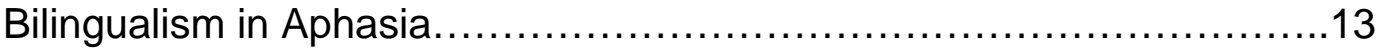

Summary and Rationale....................................................

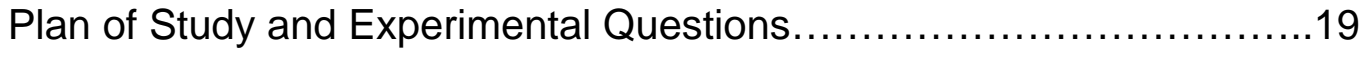

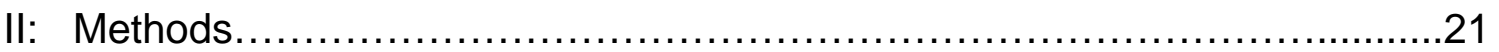

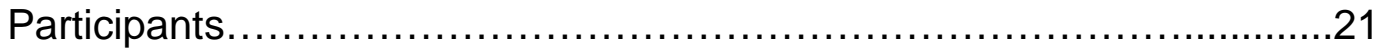

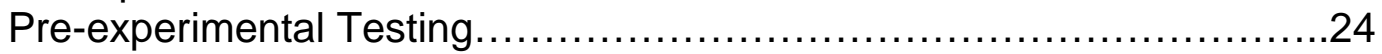

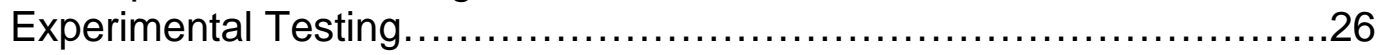

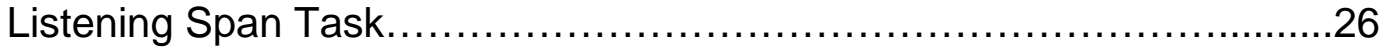

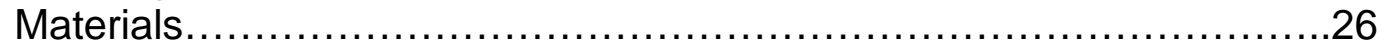

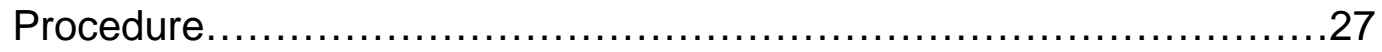

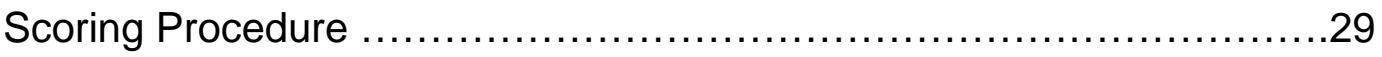

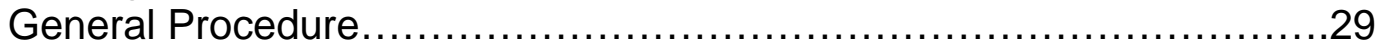

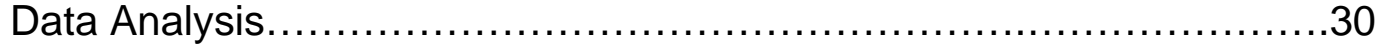

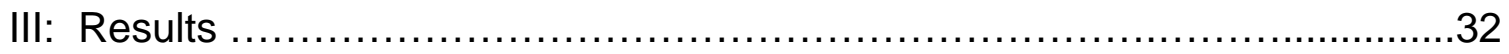

Aphasia and Working Memory............................................34

Working Memory and Auditory Comprehension............................38

Comprehension Results English Versus Spanish Aphasia..................40

Aphasia and Bilingualism.................................................41

Language Performance in Bilingual Adults with Aphasia....................42

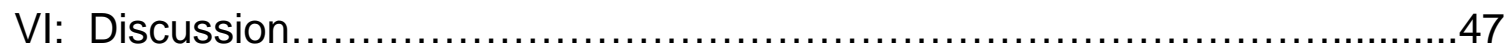

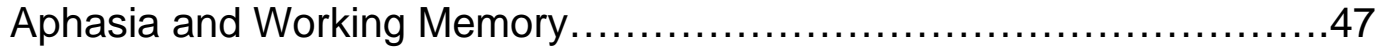

Working Memory and Auditory Comprehension...........................48

Aphasia and Bilingualism.................................................5

English and Spanish Comparison in the Group with

Aphasia on the BAT ................................................... 52

Language Performance in Bilingual Adults with Aphasia.....................53

Limitations of Current Research.........................................5

Implications for Further Research....................................... 54

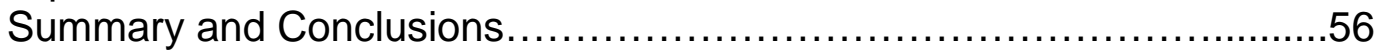




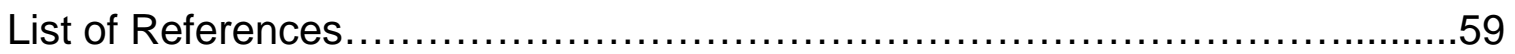

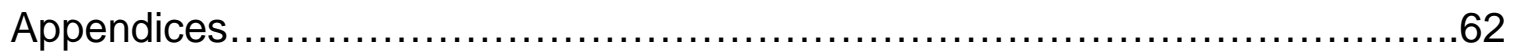




\section{LIST OF FIGURES}

FIGURE

PAGE

1. Listening Span Task (LST) Results in English in Both Groups.

2. Listening Span Task (LST) Results in Spanish in Both Groups

3. Working Memory Capacity, as measured via the LST, for the Group with Aphasia in Both Languages.

4. Pearson Product Moment Correlation Between Auditory Comprehension skills and Working Memory for both groups in English.

5. Pearson Product Moment Correlation Between Auditory Comprehension skills and Working Memory for both groups in Spanish

6. English and Spanish Results on the Token Test for the group with Aphasia.....

7. Language Proficiency Data as measured on the Boston Naming Test for the group with Aphasia in Both Languages.

8. English and Spanish Results on the Bilingual Aphasia Test for the group with Aphasia.

9. AphasiaSeverity as Measured by the BAT and Language Proficiency as Measured by the BNT in adults with aphasia in English.

10. AphasiaSeverity as Measured by the BAT and Language Proficiency as Measured by the BNT in adults with aphasia in Spanish

11. LST and BAT Results for the Group with Aphasia in English..............45

12. LST and BAT Results for the Group with Aphasia in Spanish 46 


\section{CHAPTER I}

Review of the Literature

Introduction

In the past 30 years, there has been a multitude of published research investigating aphasia, working memory, or bilingualism. However, little research has addressed the interplay of all three variables. Aphasia is a disorder of language performance and comprehension that results from damage to areas of the brain responsible for language processing. In addition to the linguistic deficits, aphasia also can result in impairments with retention of information (Burgio\& Basso, 1996; Gutbrod, Cohen, Maier \& Meier, 1987; Zurif, Caramazza, Foldi, \& Gardner, 1979). Working memory is a system involved in the temporary storage and manipulation of information (Baddeley, 2003). It has been proposed that the ability of aphasic patients to understand language may be predicted based on their working memory capacity (Caspari, Parkinson, LaPointe, \& Katz, 1998).

Relative to bilingualism, it has been reported that the number of people speaking more than one language has increased remarkably within the United States. Per the 2010 United Stated Census, $19.7 \%$ of the population speaks a language in addition to English in their homes. Thus, further investigation into the impact of aphasia on working memory capacity in bilingual adults is vital to understanding the nature as well as remediation of communication deficits experienced by bilingual individuals. 
To date, the impact of aphasia on bilingualism as well as working memory functioning has been difficult to adequately investigate. In the current study, working memory capacity will be examined in bilingual adults with and without aphasia. The review of the literature will initially address the nature of aphasia and working memory. Models of working memory will be introduced to support the connection between working memory and linguistic comprehension. Next, a discussion of bilingualism on language proficiency and bilingualism related to aphasia will be presented. This will be followed by a discussion of the limited findings examining the inter-relationship between language processing in aphasia, working memory, and bilingualism. The review of the literature will conclude with a summary and rationale, plan of study, and experimental questions for the proposed investigation.

\section{Aphasia}

Aphasia is a disorder that results from damage to the parts of the brain that are involved with language processing. Aphasia can impact spoken languages via expression and/or comprehension as well as reading, gesture, and writing. Adults with aphasia often display deficits in word retrieval, syntax, auditory attention span, processing, and memory (Caspari et al., 1998; Yu, 2010). Additionally, deficits with sensory function may result in auditory agnosia, visual agnosia, and visual field defects (Ardila\& Hough, 2013).

Research has revealed several different types of aphasia that are classified based on their specific language characteristics. Aphasias are typically 
distinguished based on spoken output and auditory and visual comprehension abilities. The extent and location of the brain damage will typically dictate the specific language characteristics affected by the aphasia (Ardila\& Hough, 2013: Darley, 1982; Davis, 2007).

\section{Language Processing in Aphasia}

Aphasia impairs the ability to comprehend and/or produce language and varies in severity across individuals. The use of functional language includes cognitive processes such as retrieval, and maintaining activation of the representations for content and knowledge of sounds, words, and/or sentences. Cognitive processes such as retrieval, processing, maintaining, and interpreting information or representations are necessary to comprehend and functionally use language (Martin \& Reilly, 2012). These processes are typically compromised in adults with aphasia. One cognitive system believed to be involved with language processing in aphasia includes working memory. Different types of aphasia result from particular sites of damage affecting specific components of the language processing system as well as impacting working memory (Ardila, 2003; Baddeley, 2003; Caramazza, 1988; Caspari, et al., 1998; Friedmann \& Gvion, 2003; Gutbrod, Cohen, Maier, \& Meier, 1987).

One cognitive process that supports word processing and verbal WM is the activation and maintenance of semantic and phonological representations of words (Martin \&Saffran, 1997; Martin, Saffran\& Dell, 1996). Language disturbances, such as those found in aphasia, affect performance on word 
processing, verbal span, verbal working memory, and verbal learning tasks and are usually the result of decay of such representations. In typical cognitive functioning, these processes operate with other abilities including rehearsal, executive functions, and attention to preserve the activation of words in shortterm memory (Martin \& Reilly, 2012).

In reference to language processing and the associated tasks in this study, it is essential to justify the rationale for using listening span. Essentially, it is necessary to distinguish between language processing of simple digit or word span tasks and the language processing and comprehension required during complex sentence tasks. Traditional digit span tasks require participants to recall a string of random numbers presented either orally or visually, depending on the skill being measured. Complex sentence tasks require participants to read a series of sentences and to manipulate the information simultaneously, such as recalling the final word of the sentence. Working memory capacity can be measured by the correct recognition of terminal words and the corresponding sentence level. The theory behind sentence recall is that the information becomes a part of working memory capacity by perceptual encoding, retrieval from long term memory, or as output of the comprehension process. Per Daneman and Carpenter (1980), this task significantly correlates with the measurement and prediction of reading comprehension when compared to simple digit span tasks. Thus, such a task is more efficient with measuring both processing and storage associated working memory (Caspari, et al, 1998). 


\section{Working Memory}

Working memory (WM) is defined as a system for temporarily storing and managing information required to carry out complex cognitive tasks (Baddeley, 2003). WM is involved in the selection, initiation, and termination of informationprocessing functions such as encoding, storing, and retrieving data (Medterms, 2013). WM is not a unitary process; additional cognitive functions associated with WM include: language comprehension, planning, reasoning, problem solving, consciousness, and second language acquisition (Ardila, 2003). More specifically, WM capacity can be defined as the total amount of resources utilized to support the processing and storage of information (Baddeley, 2003; Caspari et al., 1998; Daneman\& Carpenter, 1980). It is hypothesized that people use a common, but limited resource pool relative to their WM capacity in which information is first processed and then temporarily stored until it is no longer needed. Thus, efficient processing will result in an increased amount of information stored. If resources used to store and manage this information is measurable, it would produce an index for working memory capacity (Baddeley, 2003; Caspari et al., 1998; Daneman\& Carpenter, 1980).

It has been hypothesized that individuals with aphasia have a WM capacity that is diminished; this reduced capacity appears to negatively impact their level of comprehension (Caspari, 1998). Additional deficits can include impairment to cognitive process such as attention and executive functions (Martin \& Reilly, 2012). There is some research that suggests that as the 
functionality of the WM system decreases so does one's auditory comprehension skills and vice versa (Yu, 2010). Thisnotion is based on the work of Just and Carpenter (1992). They concluded that variations in WM capacity may be a result of variations in the available resource pool and/or processing efficiency. The limited capacity in adults with aphasia suggests that the WM deficits strongly correlate with deficits in language comprehension. Burgio and Basso (1996) reached similar conclusions. They speculated that there is a general impairment in the retention of information specific to adults with aphasia. Burgio and Basso found that patients with left hemisphere lesions and aphasia had greater difficulty with story recall tasks than a control group. Specifically, the presence of aphasia was detrimental to performance on memory tasks presented both verbally and spatially.

Models of working memory

Although there are several models that address working memory phenomena, most models have a few key common components. In the model presented by Baddeley and Hitch (1974), WM is a limited capacity system used for temporary storage and manipulation of information. The Baddeley and Hitch model consists of a central executive component that enables a person to maintain their attention long enough to process information adequately. Another component of the model is the visual or visuospatial sketchpad. The model also contains a phonological loop. Both the visuospatial and phonological loop components are commonly thought of as "slave systems" (Caspari, 1998; 
Baddeley, 1995; Baddeley, 2003). These are identified as such due to their primary functions in the working memory model. The visuospatial component strictly processes information received visually and the phonological loop processes information presented auditorally. A more recent addition to this model is the episodic buffer. The primary purpose of the episodic buffer is to store information as well as combine information from a variety of different sources or modalities into a single episode for specific coding of information (Baddeley, 2003; Paradis, 2003).

In the Baddeley (2003) model, the phonological loop functions primarily by distributing information it receives from other working memory resources. Thus, limitations in WM will cause limitations in auditory comprehension (Yu, 2010). The phonological loop of the Baddeley (2003) model can be further subdivided into 2 different components. These components consist of a storage component and a rehearsal component. The storage component of the phonological loop is believed to temporarily house information received that would otherwise be lost if not supported by the second component of the phonological loop, rehearsal. The rehearsal component ensures that the information received is maintained and organized accordingly during further processing of phonological information. Presence of these subsystems has been demonstrated through the word length effect (Baddeley, 2003). In the word length task, participants were asked to repeat a series of words that increased in length as the level of complexity increased. For instance, monosyllabic words are given to participants to be 
repeated (e.g. dog, run, start, etc.). Then the number of syllables in the set of words increases as the level of complexity increases (2 syllables words e.g. carpet, hotdog, to 5 syllable words e.g. university, institutional). However, this effect is rendered obsolete when the participant is asked to repeat the same word successively. This appears to block the memory trace through rehearsal. Moreover, it has been suggested that patients that demonstrate difficulties in repetition are not fully utilizing their phonological loop because either of the two components is impaired (Baddeley, 2003).

Additional support for this 2 component phonological loop is related to the neuroanatomical location of lesions associated with each component and the functional use for each component. The neuroanatomical locations of the rehearsal and storage components of the phonological loop have been linked to individual cortical areas via neuroimaging studies: Brodmann's area 44 for the storage component and Brodmann's area 6 and 40 for the rehearsal component (Baddeley, 2003). It is predicted that the functionality of this subdivided phonological loop facilitates language acquisition. In fact, in both children and adults, studies have shown that good working memory coincides with better second language acquisition on measures of both vocabulary and syntax (Atkins \&Baddeley, 1998). A similar effect was found among native language speakers. Specifically, it was found that good verbal memory assists acquisition of new vocabulary, which then facilitates the repetition of unfamiliar words (Baddeley, 2003). Thus, it appears that working memory capacity may be a predictor of 
performance on a variety of language processing tasks and more specifically auditory comprehension tasks.

Working Memory in Aphasia

Research in aphasia suggests that aphasia is frequently accompanied by working memory deficits (Caspari et al., 1998; Goodglass, Gleeson, \& Hyde, 1970; Gordon, 1983). This notion is most explicitly demonstrated in the study conducted by Caspari et al (1998). In this study, a modified version of the Daneman and Carpenter (1980) reading span task was utilized. Strong positive correlations were found between memory capacity, reading comprehension, and language function. In addition to Caspari et al. (1998), Burgio and Basso (1996) noted that patients with left hemisphere lesions performed significantly poorer on verbal memory and spatial memory tasks than control participants.

Friedmann and Gvion (2003) analyzed sentence comprehension and working memory limitations in aphasia. The study used an assessment tool of comprehension in 12 Hebrew-speaking individuals with conduction aphasia who had severe WM limitations. The researchers also utilized a series of 10 recall and recognition span tasks. Both of these assessments suggested that all the participants with aphasia had limited WM, which was significantly poorer than that of 146 control participants. More specifically, one half of the experiment was comprised of comprehension of relative clauses. In this study, the relative clauses required the participants to utilize semantic-syntactic reactivation. The remaining half of the experiment tested phonological reactivation. The "distance" 
between a word and its reactivation site was manipulated in three ways: by the number of words/syllables, by intervening arguments, and by intervening clauses. Results of Friedmann and Gvion (2003) revealed that individuals with conduction aphasia comprehended relative-clauses well even with long phonological and syntactic distances, and were unaffected by the distance. On the other hand, these same adults with aphasia failed to comprehend sentences that required phonological reactivation when the phonological distance was long. These results suggest that WM is closely involved with comprehension abilities within specific circumstances (when phonological reactivation is required after a long phonological distance). Overall, these results indicate that the type of reactivation required as well as the type of memory overload is necessary when analyzing the effect of WM limitation on sentence comprehension (Friedmann\&Gvion, 2003).

Another investigation examining working memory and aphasia was conducted by Brodsky, McNeil, Doyle, et al., (2003). The researchers utilized a story retelling task as an index for language ability and collected data on Serial Position Effect (SPE), which illuminates the memory component. In this study, it was proposed that the presence or absence of an SPE can determine memory limitations of participants retelling stories. More specifically, the presence of an SPE suggests that the components of memory are activated during story retelling, whereas the absence of an SPE would suggest that the cognitive process of memory is not activated during the story retelling task. Thus, the purpose of this study was to compare the SPE percentage of informational units 
produced during story retelling of adults with aphasia and age matched non-brain injured adults. The results revealed that adults with aphasia have a reduced ability to recall information, but they use the same memory functions as adults without aphasia. Both WM and one's ability to efficiently process language tightly coincide and thus directly influence ones overall linguistic performance and comprehension. Furthermore, an individual's language ability after the onset of aphasia is predictable based on their working memory capacity (Caspari, et al., 1998; Friedmann\&Givon, 2003; Goodglass, Gleeson, \& Hyde, 1970; Gordon, 1983; Haarmann, Just \& Carpenter, 1997).

\section{Bilingualism and Language Proficiency}

Cultural and linguistic differences between speakers are acquired in several ways. Firstly, a second language is acquired from infancy, or before the age of 3 , while the first language is being established simultaneously. This is known as simultaneous bilingualism (Paradis, 2011). Secondly, there are sequential bilingual speakers. Sequential bilinguals, or second language learners, begin the process of learning a second language after the first language has been firmly established (Paradis, 2011).

There are a variety of ways in which bilingualism can be classified. The most commonly accepted distinction of bilinguals is comprised of two major groups separated by age of acquisition of the second language (L2): simultaneous bilinguals and sequential bilinguals. Simultaneous bilinguals are 
those who have been exposed to two languages simultaneously from birth. Those considered to be sequential bilinguals are exposed to an L2 between the ages 3-5 years, after the first language (L1) has been established. Although at first glance is appears that there is a clear difference between types of bilingualism, in reality, proficiency in L2 varies from person to person. Types of bilingualism are better described on a continuum. Thus, there are people on one side of the continuum with high levels of proficiency in L2 in both languages, while on the other side of the continuum lie those adults who possess reduced levels of proficiency in both languages. Levels of comprehension and production of language are influenced by a variety of factors such as: age of $L 2$ acquisition, similarity between L1 and L2, language proficiency, language status, and frequency of use in L1 and L2 (Ardila\& Hough, 2013; Weekes, 2010).

Specific to language proficiency, there are two major distinctions among bilingual adults. The first major distinction is the coordinate bilingual. Coordinate bilingualism is comprised of two lexical and two semantic systems. This theory suggests that coordinate bilinguals acquire the two languages in different contexts, thus indicating that the two languages belong to independent systems. The next distinction is called compound bilingualism. Compound bilingualism suggests the presence of two lexical systems and one semantic system. This distinction implies that a bilingual person acquires two words for one concept. The final distinction is called subordinate bilingualism. In this distinction, there is one semantic system and two lexical systems. Subordinate bilingualism exists 
when language elements of a person's language are only available through elements of the other language (Ardila\& Hough, 2013).

\section{Bilingualism in Aphasia}

The effect of aphasia on bilingualism still remains a relatively poorly understood phenomenon. A goal of bilingual research after brain damage is to contribute to the development of a cognitive model for bilingual language processing in aphasia. This information has the potential to alter or improve the manner in which professionals assess and treat bilingual patients with aphasia. It is now widely accepted that bilingual aphasic adults are not impaired in the same manner and to the same degree in both languages. Therefore, it is essential to assess bilingual adults with aphasia in both languages (Ardila\& Hough, 2013; Fabbro, 2001; Paradis; 2000). Furthermore, there are large variations with regards to recovery patterns in bilingual adults with aphasia. Recovery patterns can either be parallel (where both languages recover simultaneously) or dissociated (where the pattern of recovery is different for each language), (Ardila\& Hough, 2013; Fabbro, 2001). Thus, it has been proposed that the language that recovers the best in the mother language by Ribot (1883) (as cited in Ardila\& Hough, 2013) Similarly, Pitre (1895), proposed that the language that recovers the best is the language that was most consistently used prior to the onset of the brain damage (as cited in Ardila\& Hough, 2013). Another view on language recovery in bilingual adults with aphasia is that of Paradis (2000). Per Paradis (2000), there is one main language system in bilinguals as there is in 
unilinguals. However, in bilinguals, this main language system (language spoken more often) is then subdivided into smaller systems based on the number of languages a person speaks. The main language system is susceptible to pathology just as is each individual subsystem. Paradis (2000) refers to this as the Subsystem hypothesis. The Subsystem Hypothesis suggests that although all languages used by one person have the same probability of experiencing deficits post-aphasia, recovery patterns for the main system and corresponding subsystems can vary greatly as a result of many influential factors (age of acquisition, language proficiency, language status, as well as frequency of use in L1 and L2).

The notion of activation levels and its impact on bilingual speakers with aphasia was initially presented by Pitres in1985 (as cited in Paradis, 2000, p. 57). The hypothesis consists of the idea that neural substrates of language become inaccessible after brain damage. As a result, bilinguals will inhibit one language while the other is activated to avoid interference. This is especially evident in the differential recovery patterns of language in bilingual adults. Such activation levels,enable a person to retrieve language information and eventually produce speech. According to the Activation Threshold Hypothesis, an activation threshold is met for a specific language item only once it has received a sufficient amount of positive stimulation. More specifically, the activation threshold is the amount of input necessary for the item to be activated. The amount of activation and the activation threshold are inversely related. Thus, every time a specific 
item is activated the lower the activation threshold becomes for that item, thus making it more readily accessible because fewer impulses are needed to activate it. However, the same is true in the opposite direction. If an item is not stimulated over a long period of time, attrition occurs making it harder to activate (Paradis, 2000). Nevertheless, normal activation threshold levels are also affected by outside factors such as aging or brain pathology. Such disturbances to the normal activation thresholds cause the activation threshold to rise at the level of the main language system, at the subsystem level of language one (L1), language two (L2), or both. The systems can be affected individually or simultaneously (Fabbro, 2001; Paradis, 2000). With respect to activation levels, it appears that complete comprehension of an item requires a smaller amount of impulses or stimulation than is required for production. This results in comprehension tasks being easier to complete than production tasks. This occurs because an item is activated by the impulses generated by the stimulus as it reaches the senses (Green, 1986; Paradis, 2000; Paradis, 1993).

Paradis (2000) also explained that both bilingual and unilingual speakers can make efforts to counterbalance such a change in their activation threshold, especially those with aphasia. The two ways in which the compensation can be made are through the use of right brain pragmatic functions of language and use of metalinguistic knowledge. Pragmatic functions in the right hemisphere are used in an effort to compensate for the lapse in linguistic competence in a second language. This assists individuals in deriving meaning and context 
specific, appropriate use of a second language which facilitates language learning and comprehension (Paradis, 2000). Metalinguistic knowledge of the second language is essential when attempting to learn it and become fully competent. This skill requires an individual to attend to the idea of language in a concrete form that requires additional effort, unlike that of a first language. Complete attention, memory, and recall all comprise the concept of metalinguistic knowledge and impact a person's capability to learn, retain, and produce a second language or regain a first language, as in the case with many aphasic patients (Paradis, 2000). Overall, it is important to recognize that what applies to the bilingual brain is the same as what applies to the unilingual brain and the motivation of the speaker to communicate in both languages can greatly influence their ability to acquire a new language and maintain functional use of that language.

The current bilingual model proposes that bilinguals have a shared semantic system and matching lexical representations for each language (Kiran\& Roberts, 2010). This model goes on to suggest that treatment plans for bilingual adults with aphasia should focus on semantic features to increase activation levels for items trained and semantically similar items. However, results of such treatment plans will vary depending on the individual. Factors such as level of proficiency in L1 and L2, language dominance, age of acquisition, and frequency of use will all greatly impact the results of such a treatment plan. 
As a whole, reports on performance results on memory tasks in bilinguals vary from study to study. There have been reports on equal performance in both languages, reports of bilingualism as an advantage, as well as reports of bilingualism as a disadvantage. It appears that the results are specific to the memory task administered (Ardila, Rosselli, Ostrosky-Solis, et al., 2000).

Summary and Rationale.

Research has revealed an association between aphasia and working memory deficits. This association is observed in that as linguistic skills are decreased as a result of aphasia; working memory capacity is also reduced. Working memory is the temporary storage and manipulation of information that can be utilized for many cognitive functions. This association between working memory and aphasia is also believed to be present in bilingual adults with aphasia.

Influential components of bilingualism include: the dominant language, language proficiency in L1 and L2, motivation to recover both languages, language status, as well as age of acquisition. Most importantly, bilingualism cannot be classified as one concrete level, but rather a person's level of bilingualism falls somewhere on a wide range. This range of bilingualism goes from one end where people acquire very high levels of proficiency in both comprehension and production of spoken language skills in both tongues; on the opposite end bilingual adults acquire variably decreased levels of proficiency in understanding and/or speaking skills in both languages. This wide range of 
bilingualism suggests that, patterns of bilingualism in adults with aphasia also vary depending on the individual and are rarely found to be equal in both languages. Taken as a whole, working memory capacity appears to influence learning a second language. WM capacity is related to language performance and reading comprehension in neurologically impaired populations, such as adults with aphasia. We propose that when working memory capacity is more proficient and similar to typical functioning in an adult with aphasia, overall severity of aphasia is expected to be reduced in bilinguals as it would in monolinguals.

Further investigation is needed in this area for a variety of reasons. Firstly, the impact of aphasia and working memory is still developing. Although connections between the two have been proposed (e.g. decreased memory is related to decreased auditory comprehension skills are the onset of aphasia), additional research is necessary in further support this notion. Secondly, research on bilingualism and working memory is nearly non-existent. Although there is a rapidly growing trend of bilingualism in the United States, available research in this area is still limited. Minimal levels of research on bilingualism have provided us with a brief introduction to patterns of acquisition and patterns of recovery in this population. Specific characteristics of bilingualism, particularly of bilingual adults with aphasia are not available. Another rationale for this study is to shed some light on the relationship between the two and how one might impact the other and vice versa. Finally, obtaining additional information on the relationship between aphasia, working memory, and their association to 
bilingualism can greatly impact the manner in which professionals assess these components, analyze results relative to the known information about working memory and aphasia in monolingual adults, as well as the intervention approaches for clients that may fall into these criteria.

\section{Plan of Study and Experimental Questions}

The purpose of this study was to investigate: 1) the impact of aphasia on working memory capacity; 2) the influence of working memory on language production and comprehension; 3) the influence of aphasia on bilingualism in adults; and 4) the impact of working memory on bilingual adults with and without aphasia. In the current study one group of bilingual adults aged 26-91 years of age without aphasia was compared to a group of bilingual adults ages 26-91 years of age in regards to their working memory skills (listening span task), the language proficiency (BNT), and auditory comprehension skills (Token Test). The following experimental questions were answered:

1) Is there a significant difference in performance between the two groups in working memory between as measured via the listening span task?

2) Is there a significant relationship between WM, as measured by the listening span task, and auditory comprehension skills, as measured by the Token Test, in both or either group?

3) Does the presence of aphasia influence bilingualism as measured by differential performance in both languages on the BNT? 
4) Is there a significant relationship between language performance on the BAT and BNT in the bilingual adults with aphasia? 


\title{
CHAPTER II
}

\author{
Method
}

\section{Participants}

Sixteen participants from the greater Miami area were recruited via convenient sampling to participate in the study. Over100 nursing home facilities were contacted via telephone to obtain information regarding willing participants. Bilingual adults without aphasia were obtained via flyer advertisement and word of mouth. All participants were bilingual with varying degrees of proficiency. No matching was possible for the study as a result of limited participation. T tests conducted between the two groups for educational level in years and age in years indicated that there were no significant differences between the two groups relative to these variables (Education: $t=-0.2506 ; p>.05 ;$ Age; $t=-1.9261 ; p$ $>.05)$. The first group was comprised of eight participants that are bilingual adults with aphasia as a result of left hemisphere stroke. The second group was comprised of eight participants that are bilingual adults without aphasia. Inclusion criteria for the bilingual adults without aphasia consisted of: adults between the ages of 25-95 years, no history of neurological damage, language proficiency in two languages, as well as vision and hearing that is within normal limits.

Bilingual adults with aphasia were selected based on the following criteria: level of chronicity in time post-onset stroke, handedness, as well as proficiency in language 1 (L1) the dominant language and proficiency in language two (L2). Time post-onset of neurological damage resulting in aphasia was noted but not 
controlled. All typical participants achieved a cut-off score of at least 13 out of 36 on the Token Test(De Renzi\&Faglioni, 1978) to be included in the study. The bilingual adults with aphasia achieved a score of at least 8 out of the 36 items on the Token Test to be eligible for participation. All participants were right handed. Language proficiency, as measured by the shortened form of the Boston Naming Test (Goodglass, Kaplan, \&Weintraub,1983), in both languages, will be determined via a minimum score of 12 out of 15 for the adults without aphasia and a minimum score of 3 for the adults with aphasia. All participants had a minimum education level equivalent to at least the 6th grade to ensure full comprehension of the experimental tests. Demographic information for all of the participants of this investigation is summarized in Table 1. The demographic information includes the following per participant report: gender, age in years, education in years, date of onset of CVA for the adults with aphasia, type of bilingual acquisition, country origin, dominant language, as well as type of aphasia where available 
Table 1.Demographic information for participants.

\begin{tabular}{|c|c|c|c|c|c|c|c|c|}
\hline Name & Gender & $\begin{array}{l}\text { Age } \\
\text { in } \\
\text { Years }\end{array}$ & $\begin{array}{c}\text { Educatio } \\
\mathrm{n} \text { Level } \\
\text { in years }\end{array}$ & $\begin{array}{c}\text { Date of } \\
\text { Onset } \\
\text { in years } \\
\text { past }\end{array}$ & $\begin{array}{l}\text { Sequential } \\
\text { or } \\
\text { Simultaneo } \\
\text { us Bilingual } \\
\text { Acquisition }\end{array}$ & $\begin{array}{l}\text { Country } \\
\text { of Birth }\end{array}$ & $\begin{array}{c}\text { Language } \\
\text { Dominance } \\
\text { per } \\
\text { Participant } \\
\text { Report }\end{array}$ & $\begin{array}{l}\text { Type of } \\
\text { Aphasia }\end{array}$ \\
\hline \multicolumn{8}{|c|}{ Nonaphasic Group } & \\
\hline 1 & $F$ & 54 & 18 & $\mathrm{~N} / \mathrm{A}$ & $\begin{array}{l}\text { Simultaneo } \\
\text { us }\end{array}$ & U.S.A. & English & $\mathrm{N} / \mathrm{A}$ \\
\hline 2 & $M$ & 30 & 14 & N/A & $\begin{array}{l}\text { Simultaneo } \\
\text { us }\end{array}$ & U.S.A. & English & N/A \\
\hline 3 & $F$ & 54 & 16 & $\mathrm{~N} / \mathrm{A}$ & $\begin{array}{l}\text { Simultaneo } \\
\text { us }\end{array}$ & U.S.A. & English & N/A \\
\hline 4 & $F$ & 73 & 6 & N/A & Sequential & $\begin{array}{l}\text { Puerto } \\
\text { Rico }\end{array}$ & English & N/A \\
\hline 5 & $F$ & 47 & 16 & $\mathrm{~N} / \mathrm{A}$ & $\begin{array}{l}\text { Simultaneo } \\
\text { us }\end{array}$ & U.S.A. & Equal & N/A \\
\hline 6 & $M$ & 28 & 16 & N/A & $\begin{array}{l}\text { Simultaneo } \\
\text { us }\end{array}$ & U.S.A. & English & $\mathrm{N} / \mathrm{A}$ \\
\hline 7 & $M$ & 26 & 16 & N/A & $\begin{array}{l}\text { Simultaneo } \\
\text { us }\end{array}$ & U.S.A. & English & N/A \\
\hline 8 & $M$ & 83 & 12 & N/A & $\begin{array}{l}\text { Simultaneo } \\
\text { us }\end{array}$ & U.S.A. & Spanish & N/A \\
\hline \multicolumn{8}{|c|}{ Aphasic Group } & \\
\hline 9 & $F$ & 68 & 12 & 3 & Sequential & Cuba & Spanish & $\mathrm{N} / \mathrm{A}$ \\
\hline 10 & $F$ & 51 & 16 & 11 & $\begin{array}{l}\text { Simultaneo } \\
\text { us }\end{array}$ & $\begin{array}{l}\text { Argenti } \\
\text { na }\end{array}$ & English & $\begin{array}{l}\text { Non- } \\
\text { Fluent }\end{array}$ \\
\hline 11 & $F$ & 49 & 16 & 13 & Sequential & U.S.A. & English & $\begin{array}{l}\text { Non- } \\
\text { Fluent }\end{array}$ \\
\hline 12 & $M$ & 59 & 16 & 0.5 & Sequential & Cuba & Spanish & $\mathrm{N} / \mathrm{A}$ \\
\hline 13 & $F$ & 61 & 13 & 1 & Sequential & Cuba & English & Fluent \\
\hline 14 & $F$ & 76 & 16 & 1 & Sequential & Cuba & Equal & $\mathrm{N} / \mathrm{A}$ \\
\hline 15 & $M$ & 91 & 12 & 1 & Sequential & Cuba & Spanish & Fluent \\
\hline 16 & $F$ & 80 & 16 & 6 & $\begin{array}{l}\text { Simultaneo } \\
\text { us }\end{array}$ & $\begin{array}{l}\text { Puerto } \\
\text { Rico }\end{array}$ & Equal & Fluent \\
\hline Mean & $x$ & $\begin{array}{l}58.12 \\
5\end{array}$ & 14.4375 & 4.5625 & $x$ & $x$ & $x$ & $x$ \\
\hline
\end{tabular}




\section{Pre-experimental Testing}

All participants passed a hearing screening through the speech frequencies (25dB HL at 1000, 2000, and $4000 \mathrm{~Hz}$ ), (American SpeechLanguage Hearing Association Audiologic Assessment Panel, 1996). A short form of the Token Test (De Renzi\&Faglioni, 1978) was then administered to both groups. The Token Test is utilized to determine auditory comprehension level and presence of subtle memory impairments when applicable.

The Bilingual AphasiaTest (BAT) (Paradis, 1987) was administered to the group with aphasia to determine their level of severity of aphasia in both languages (Fabbro, 2001). Culturally and linguistically equivalent EnglishSpanish version of the test battery was administered to assess each language of a bilingual individual in an equivalent manner (Ardila\& Hough, 2013). Furthermore, the syntactic comprehension portion of the BAT is also appropriate to assess L2 processing given the time alterations described in Achim and Marquis (2011). In addition to the comprehension portion, the BAT is useful because the ceiling performance in L2 is seldom reached, thus verifying that the BAT is an appropriate tool for measurement of an individual's L2. Lastly, per Achim and Marquis (2011), errors found in L2 are consistent with a lack of language processing automaticity and can assist one in differentiating the varying levels of spoken language comprehension in L2.

The English-Spanish version of the BAT is comprised of four major parts:

1. Word recognition, 2. Translation of words, 3. Translation of sentences, and 4. Grammaticality judgments. All four portions of the English-Spanish BAT were 
administered during the study. Tasks administered include: verbal comprehension, following simple and complex directions, syntax comprehension, categorical semantics, repetition of words and phrases, and constructing sentences. The language background and spontaneous language tests were not utilized for the purpose of this study, however, informal language background information was obtained via participant interview. Comprehension skills of bilingual adults were compared against the monolingual comprehension results of the Token Test to ensure that all participants have appropriate levels of comprehension to complete the remaining experimental tasks.

The short form of the Boston Naming Test (BNT) was utilized to assess the level of language proficiency in both the experimental and control groups in both languages. This test determined whether adequate levels of language proficiency in both languages were present in each participant in order to participate fully in the experimental task. An adapted version of the BNT in Spanish was administered to compare results in English and Spanish in both aphasic and non-aphasic participants. A criterion score of 12 was set for adults without aphasia; a criterion score of 2 was set for the adults with aphasia to be allowed to partake in the study. The test was administered in both languages to measure proficiency in each individual language. 


\section{Experimental Testing}

\section{Listening Span Task}

The experimental task consists of a series of listening span tasks that were administered to measure each participant's working memory capacity. The listening span task is based on the work of Caspari et al. (1998) and others (Daneman\& Carpenter, 1980; LaPoint\& Engle, 1990). The task includes sentences at five levels. Each level increases with difficulty via adding one more sentence than the previous level. Sentences are three to seven words in length including a word that is to be recalled after the end of each sentence. This word is called the terminal word. The sentences used are both active and declarative while the terminal words are either nouns or verbs that occur frequently in English and concrete in nature. The information was presented orally via a computer recording. Auditory information consisted of: instructions for each task, stimuli presented, questions to participants regarding the stimuli, as well as response options for the patients. After reading the sentences to each participant, they were then asked to identify the terminal word of each sentence by pointing to a corresponding picture. Participants were assessed in both their first and second languages (English and Spanish).

Materials.

The stimulus materials used throughout the listening span task included high frequency words obtained from Kucera and Francis' (1967) ranked list of words used in the English language based on the frequency and familiarity of 
their use. Terminal words and their foils all consisted of nouns. Additionally, 1-2 syllable words were utilized for the sentences constructed, terminal words, as well as the foil options (e.g. "dog," and "vaso"). Terminal words are not repeated throughout the 5 levels of the listening span task and are chosen randomly to be paired with sentences that are unrelated to the word. Foils also are chosen at random from the Kucera and Francis (1967) word frequency list and randomly paired with terminal words that are unrelated. Concrete sentences were also constructed using the Kucera and Francis (1967) high frequency word list. The concrete and declarative sentences ranged between 3-7 word sentences containing only one clause (e.g. "The sun will rise"). Computer generated images were obtained from the Google search engine and implemented into the experimental listening span task. All images obtained were concrete line drawings that were readily identifiable and relatable to the target words.

\section{Procedure}

First, participants were asked to listen to a sentence or sentences read aloud by the primary investigator and remember the terminal word for later recall. The participants were also asked to answer questions about the sentences after the recognition task. Three practice trials were performed in order to ensure that the participants understand the task requirements. The sentences were administered orally to facilitate complete comprehension. The sentences were presented orally with normal intonation and at a rate of approximately 3-4 words 
per second on a computer screen. Results were tallied by the investigator on the data collection sheet (Appendix B).

As mentioned, each level consisted of five trials, and each trial is comprised of one sentence and one terminal word. Each participant was shown one typed sentence and one terminal word in Arial font, size 16 on the computer. This information was read orally via an audio recording. Next, the image of the corresponding picture of the target word and two foil pictures was presented. Two foils are assigned to each correct terminal word. Participants were then asked to identify the target picture by pointing. This concludes the first trial. In order for the participant to advance to the proceeding level the participant had to choose the correct target picture in three out of the five trials, otherwise the test was discontinued.

During the next level, the second level, the participants were given another stimulus with two sentences and two terminal words. The information was read aloud in consecutive order. One sentence was presented at a time. Following the oral presentation, the display consisted of the pictures of both target words and their corresponding foils. Participants were asked to point to both target pictures regardless of order. As with the first level, participants were expected to select all of the target pictures for at least three of the five trials in order to proceed to the next level. Each progressive level included an additional sentence and terminal word to be recalled for later recognition. Progression 
through the advancing level was ceased when participants did not choose the correct target pictures in at least three out of five trails at any level.

\section{Scoring Procedure}

During the first level, a listening span measurement of 1.0 was given to the participant when they correctly identified the target picture on at least three out of the five trials. At the second level, a measurement of 2.0 was given if the participant chooses the target pictures on at least three out of the five trials. Partial credit of 0.5 will be given when participants correctly select the target pictures in two of the three trials at a level. A measurement of 1.5 or lower was labeled as a low span working memory measurement. A measurement of 3.0 or higher was labeled a high span working memory measurement. All data was recorded on the data collection sheet.

\section{General Procedures}

Participants were recruited from the community. Both the pre-experimental and experimental tests were conducted at either Florida International University in the Academic Health Center 3 (AHC-3) building on the $4^{\mathrm{TH}}$ floor conference room, the participant's residence, or their place of business. The study was approved by the University Institutional Review Board at Florida International University. A copy of the university Informed consent forms is available in Appendix A. Copies of each were given and read aloud to each participant in this study by the primary investigator. Benefits of the study were also explained to each participant by the primary investigator. Additional time and explanation of 
documentation was provided to participants as needed. The informed consent was understood and signed by each participant prior to any experimentation.

Each participant was assessed in a quiet environment. As mentioned, the pre-experimental tests administered included the following: hearing screening, a modified version of the Token Test, the Bilingual Aphasia Test, as well as the short form Boston Naming Test. The experimental assessment included the listening span task. The total task administration lasted approximately 1-2 hours per participant and was conducted in one session.

\section{Data Analysis}

T tests were conducted to determine significant differences for the following comparisons: Working memory capacity, as measured via the LST, between groups for both languages and between languages for each group; auditory comprehension, as measured by the Token Test, between English and Spanish for the group with aphasia; language proficiency (BNT) between English and Spanish for both groups; and aphasia severity (BAT) between English and Spanish for the group with aphasia.

Pearson product correlations were computed examine relationships between the following variables: working memory (LST) and auditory comprehension (Token Test) for both groups in English and Spanish; language performance on the BAT and BNT in both languages; WM and aphasia severity (BAT) in the group with aphasia in English and Spanish; and language 
proficiency, as measured by the BNT, and aphasia severity, as measured by the BAT, in both languages for the group with aphasia. 


\section{CHAPTER III}

\section{Results}

The purpose of the study was to investigate the impact of aphasia on working memory in bilingual adults. The study also considered the following influential factors: auditory comprehension skills, language proficiency in both the English and Spanish languages, as well as aphasia severity in relation to working memory. These factors were also analyzed in relation to one another. The experimental questions of the study addressed the difference in performance between the two groups in working memory as measured via the listening span task; the relationship between WM, as measured by the listening span task, and auditory comprehension skills, as measured by the Token Test, in both the aphasic and non-aphasic groups; the influence of bilingualism on aphasia as measured by differential performance in both languages on the BNT; and the relationship between language performance on the BAT and BNT in the bilingual adults with aphasia. The mean, standard deviation, and range for the above mentioned assessment measures are presented in Table 2 for English. Table 3 is a display of assessment results in Spanish. 
Table 2. Means standard deviations, and ranges for auditory comprehension, language proficiency, aphasia severity, and working memory capacity in English for both groups

\begin{tabular}{|c|c|c|c|c|}
\hline ENGLISH & $\begin{array}{c}\text { Auditory } \\
\text { Comprehension- } \\
\text { Modified Token Test }\end{array}$ & $\begin{array}{c}\text { Language } \\
\text { Proficiency- } \\
\text { BNT }\end{array}$ & $\begin{array}{c}\text { Aphasia } \\
\text { Severity- } \\
\text { BAT }\end{array}$ & $\begin{array}{c}\text { Working } \\
\text { Memory- } \\
\text { Listening Span } \\
\text { Task }\end{array}$ \\
\hline \multicolumn{5}{|c|}{ Non-aphasic Group } \\
\hline Mean & 33.625 & 13.250 & N/A & 13.250 \\
\hline $\begin{array}{c}\text { Standard } \\
\text { Deviation }\end{array}$ & 6.718 & 1.035 & N/A & 4.950 \\
\hline Range & $13-36$ & $12-15$ & N/A & $1-15$ \\
\hline \multicolumn{5}{|c|}{ Aphasic Group } \\
\hline Mean & 20.75 & 6.875 & 14.500 & 2.438 \\
\hline $\begin{array}{c}\text { Standard } \\
\text { Deviation }\end{array}$ & 9.618 & 4.190 & 5.237 & 3.396 \\
\hline Range & $10-36$ & $2-14$ & $8-21$ & $0.5-10.5$ \\
\hline
\end{tabular}

Table 3. Mean, standard deviations, and ranges for auditory comprehension, language proficiency, aphasia severity and working memory capacity in Spanish for both groups.

\begin{tabular}{|c|c|c|c|c|}
\hline SPANISH & $\begin{array}{c}\text { Auditory } \\
\text { Comprehension- } \\
\text { Modified Token Test }\end{array}$ & $\begin{array}{c}\text { Language } \\
\text { Proficiency- } \\
\text { BNT }\end{array}$ & $\begin{array}{c}\text { Aphasia } \\
\text { Severity- } \\
\text { BAT }\end{array}$ & $\begin{array}{c}\text { Working } \\
\text { Memory- } \\
\text { Listening Span } \\
\text { Task }\end{array}$ \\
\hline \multicolumn{5}{|c|}{ Non-aphasic Group } \\
\hline Mean & 33.125 & 13.250 & N/A & 13.313 \\
\hline $\begin{array}{c}\text { Standard } \\
\text { Deviation }\end{array}$ & 8.132 & 0.744 & N/A & 4.773 \\
\hline Range & $13-36$ & $12-14$ & N/A & $1.5-15$ \\
\hline \multicolumn{5}{|c|}{ Aphasic Group } \\
\hline Mean & 21.250 & 6.875 & 14.375 & 2.625 \\
\hline $\begin{array}{c}\text { Standard } \\
\text { Deviation }\end{array}$ & 9.957 & 2.949 & 4.838 & 3.335 \\
\hline Range & $8-36$ & $3-12$ & $7-19$ & $0.5-10.5$ \\
\hline
\end{tabular}




\section{Aphasia and Working Memory}

The first experimental question considered the difference in performance for working memory, as measured by the listening span task, in the aphasic group compared to the non-aphasic group. To determine significant differences in performance, a t-test was conducted, using a $p$ value of 0.05 . The results revealed that working memory capacity, as measured by the listening span task, was significantly higher for the non-aphasic group than the aphasic group in both English ( $t=5.094851 ; p<0.0008)$ and Spanish $(t=5.191361 ; p<0.0006)$.

A score of 1.5 or lower is labeled as a low working memory span. A measurement of 3.0 or higher is labeled as high working memory span. Only one participant in the non-aphasic group obtained a score that was considered low working memory span (a score of 1 in English and a score of 1.5 in Spanish). All of the other participants in the non-aphasic group scored 3.0 or above. For the aphasic group, 5 participants obtained scores on the listening span task that were considered low working memory SPAN (span scores between 0.5-1.5 in both English and Spanish). The remaining three aphasic participants obtained scores that were high working memory span (3.0 or above). Table 4 includes the LST data for both groups in English and Spanish. 
Table 4. LST results for the non-aphasic and aphasic group in English and Spanish.

\begin{tabular}{|c|c|c|c|}
\hline $\begin{array}{c}\text { LST English } \\
\text { Non Aphasic }\end{array}$ & $\begin{array}{c}\text { LST Spanish-Non } \\
\text { Aphasic }\end{array}$ & $\begin{array}{c}\text { LST English } \\
\text { Aphasic Group }\end{array}$ & $\begin{array}{c}\text { LST Spanish } \\
\text { Aphasic Group }\end{array}$ \\
\hline 15 & 15 & 0.5 & 1 \\
\hline 15 & 15 & 1 & 1.5 \\
\hline 15 & 15 & 10.5 & 10.5 \\
\hline 1 & 1.5 & 1.5 & 3 \\
\hline 15 & 15 & 3.5 & 3 \\
\hline 15 & 15 & 1 & 1 \\
\hline 15 & 15 & 1 & 0.5 \\
\hline 15 & 15 & 0.5 & 0.5 \\
\hline
\end{tabular}

Overall, 9 participants (both non-aphasic and aphasic) achieved working memory spans that were considered to be high spans in English. Ten total participants across groups achieved scores that are considered high working memory span on the Spanish LST. A scatter plot of the listening span task results for both groups in English are displayed in Figure 1; the results of the listening span task in Spanish are displayed in Figure 2 for both groups. 
Figure 1.ListeningSpanTask (LST) Results in English in Both Groups.

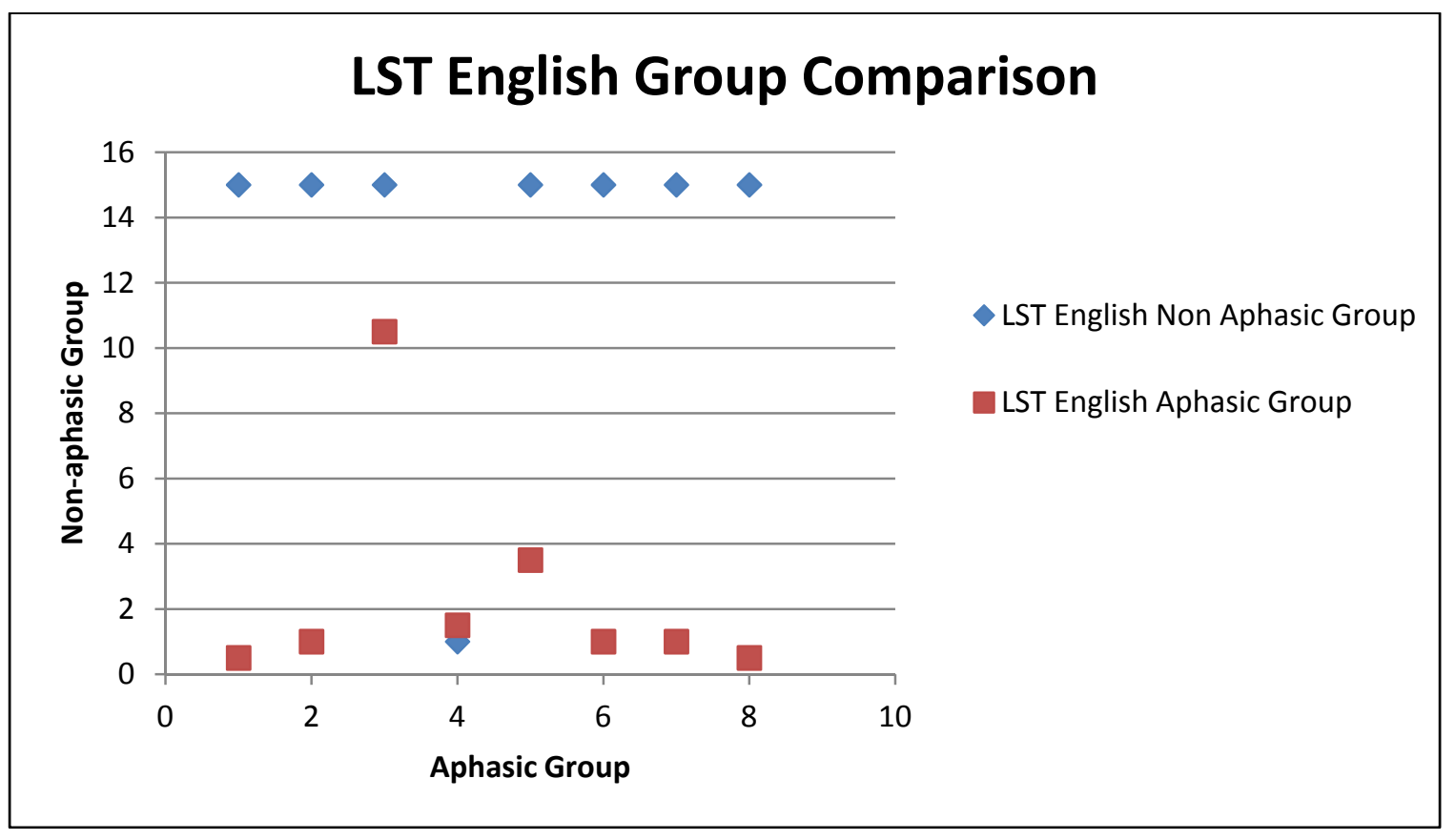

Figure 2.ListeningSpanTask (LST) Results in Spanish in Both Groups.

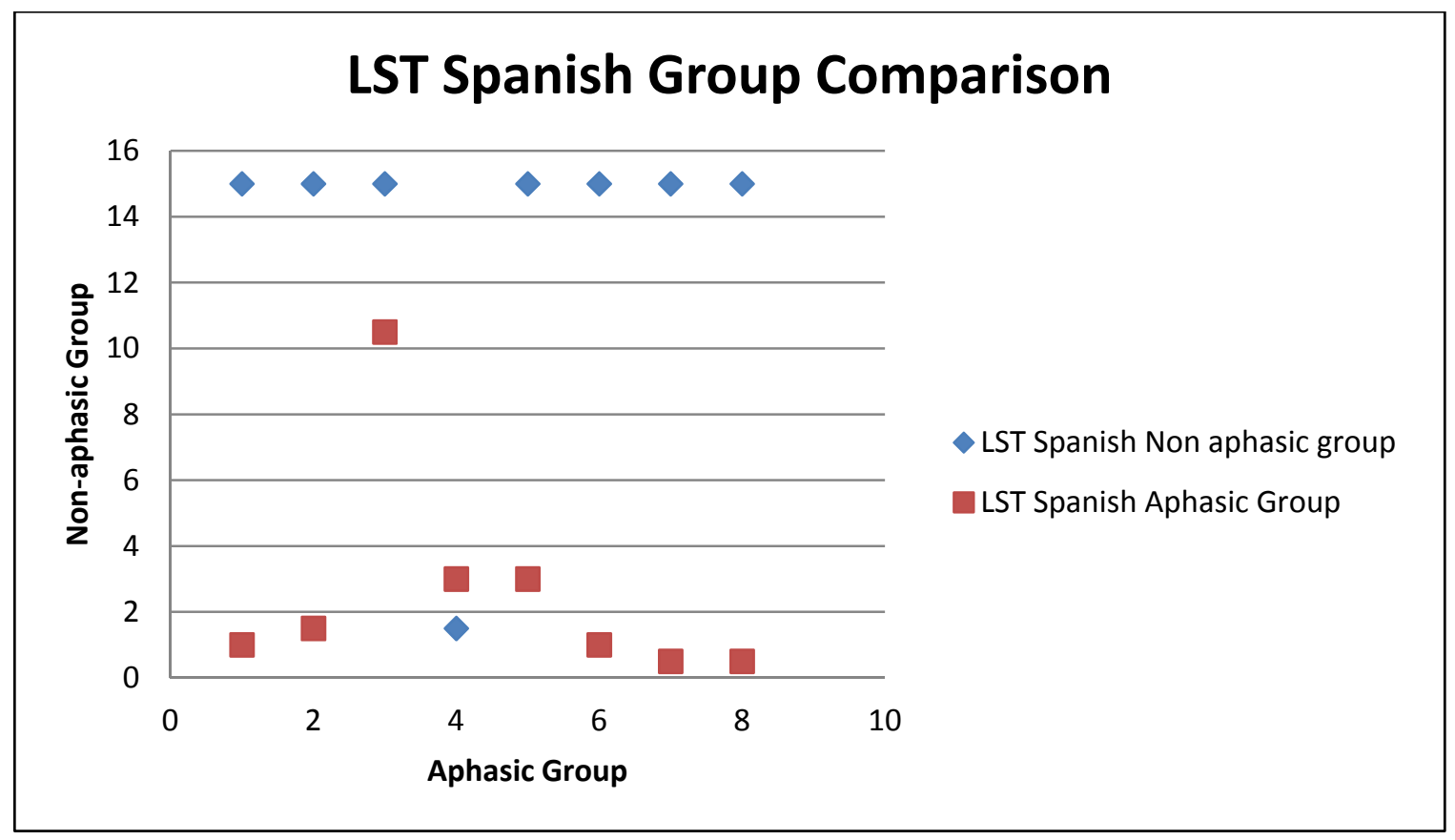


Results on the listening span test in English were compared to results in Spanish for both groups. As can be seen on Table 4, results for the non-aphasic group were equivalent for the two languages. For the aphasic group, a t-test, with an alpha level of .05, was conducted to examine significant differences between the two sets of data. For the aphasic group, the findings were not significant $(\mathrm{t}=$ $0.81435, p>.05)$, suggesting that bilingualism did not impact working memory capacity for this sample of bilingual adults with aphasia. Figure 3 is a display of the working memory capacity data, as measured by the listening span task, in scatter plot form, for the aphasic group in both languages.

Figure 3.Working memory capacity, as measured via the LST, for the group with aphasia in both languages.

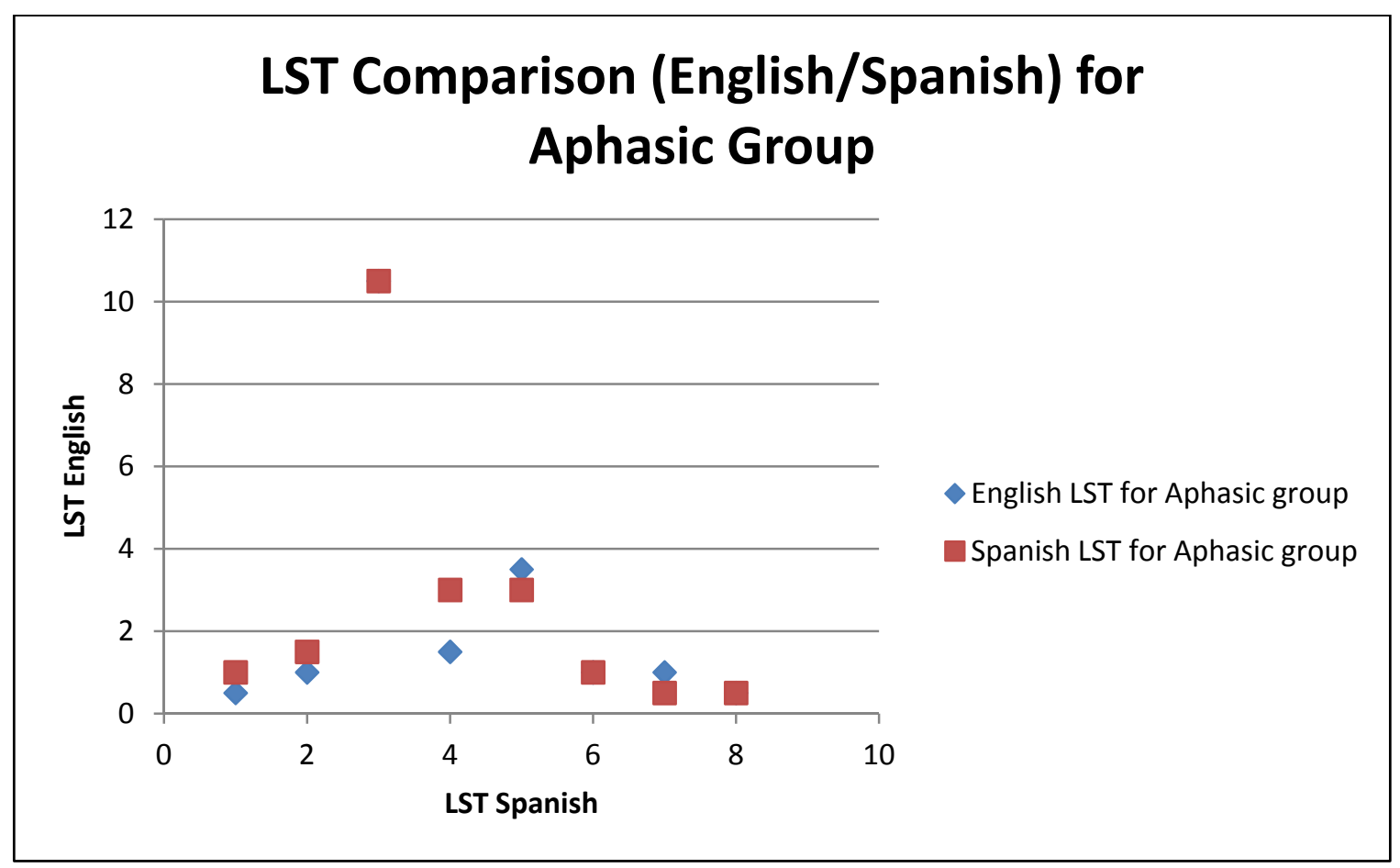




\section{Working Memory and Auditory Comprehension}

The second experimental question addressed the relationship between WM, as measured by listening span, and auditory comprehension, as measured by the Token Test, for both groups in English and Spanish. Pearson Product Moment correlations were conducted between Token Test scores and listening span task scores in both languages for each group. Highly significant and strong positive correlations $(r=1 ; p<.001)$ were observed between auditory comprehension skills and working memory for the non-aphasic group for both English and Spanish. Strong positive correlations also were observed for the group of aphasic adults in both languages $(r=0.78, p<.001)$. A scatter plot displayed below in Figure 4 provides a visual representation of the relationship of working memory (as measured via the LST) and auditory comprehension skills (as measured by the Token Test) for both the non-aphasic and the group with aphasia in English. Figure 5 is a display of the results in Spanish. Correlation tables for these analyses are in Appendix C. 
Figure 4.Pearson Product Moment

correlationsbetweenauditorycomprehensionskills and working memory for both participant groups for English.

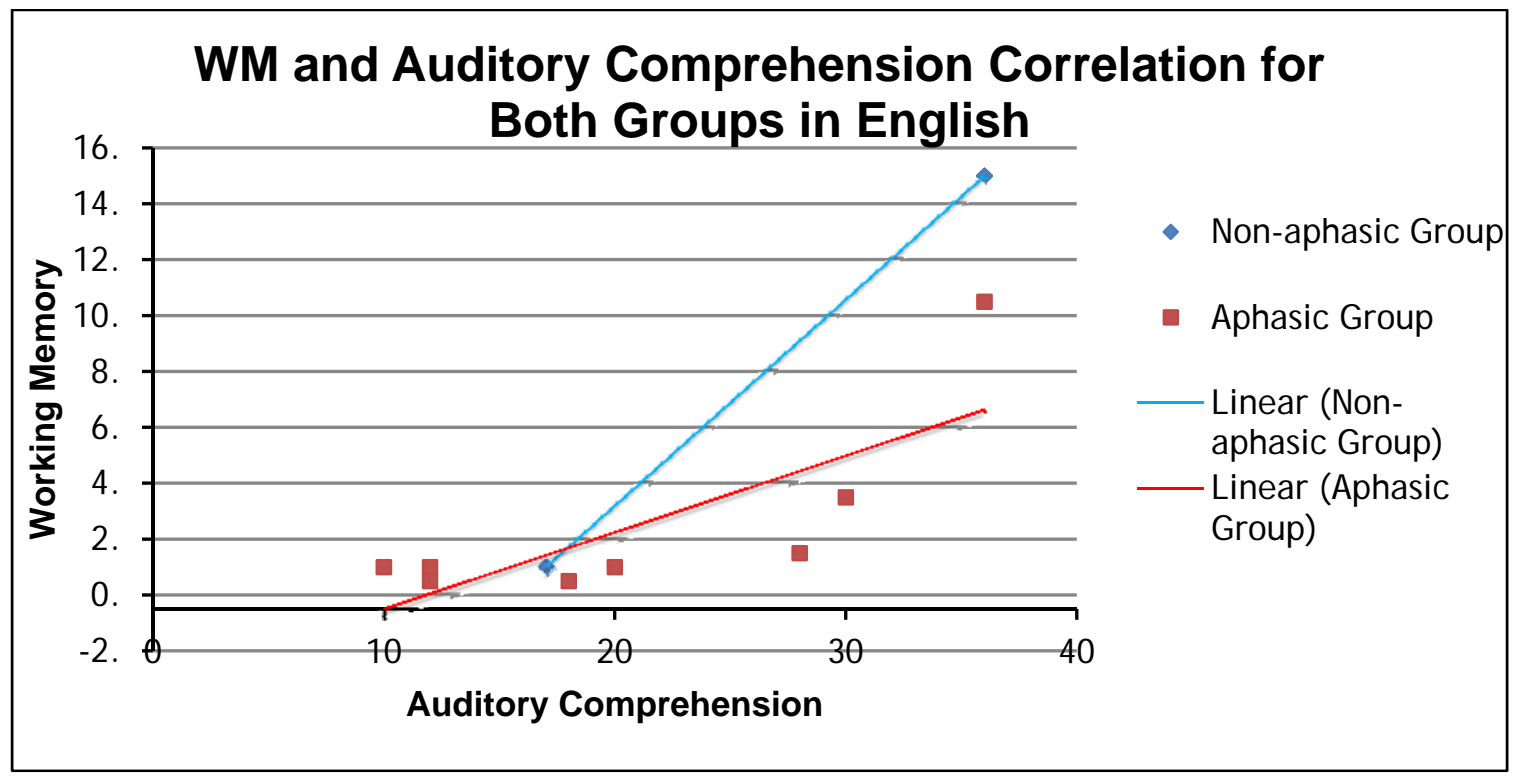

Figure 5. Pearson Product Moment correlationsbetweenauditorycomprehensionskills and working memory for both participant groups for Spanish.

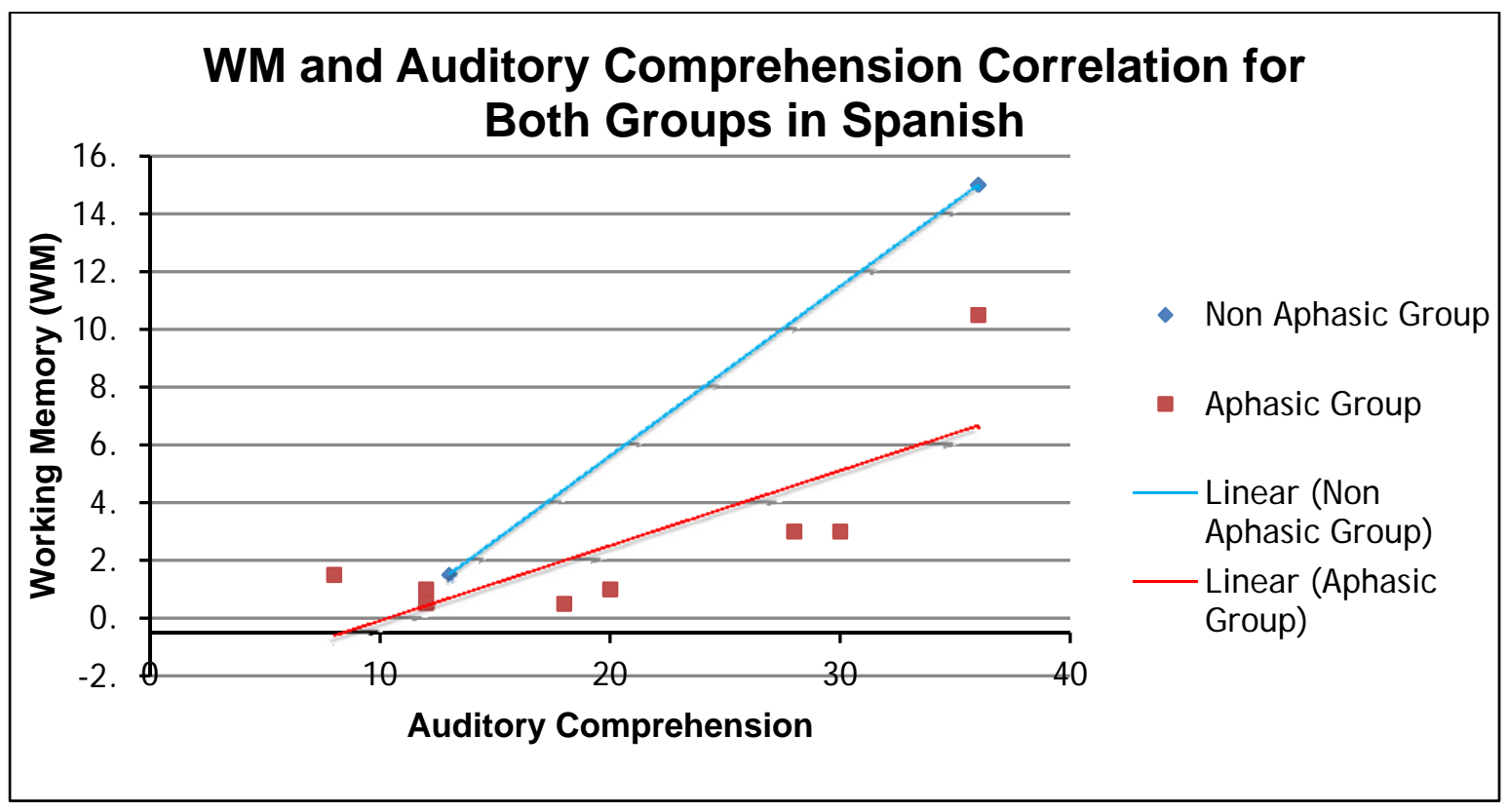


Comprehension Results English Versus Spanish Aphasia

A t-test was conducted between Spanish and English results on the Token Test for aphasic adults. The findings were not significant $(t=1 ; p>.05)$. These results indicate that there is no significant difference between English and Spanish relative to auditory comprehension in the group with aphasia. Figure 6 is a display of the Token Test data in scatter plot form for the aphasic group in both languages.

Figure 6. English and Spanishresults on Token Test for the group withaphasia.

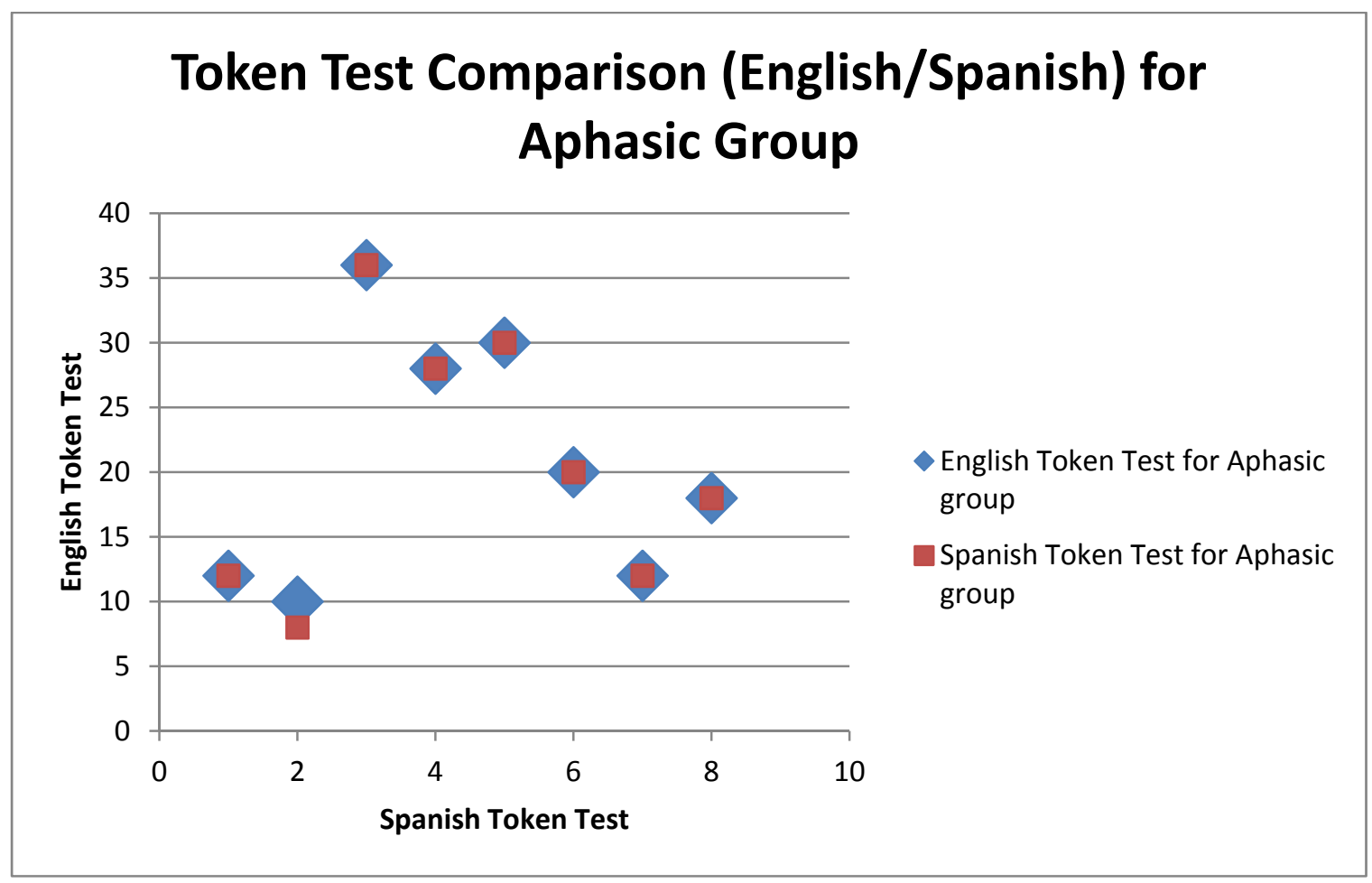




\section{Aphasia and Bilingualism}

The third experimental question takes into consideration the influence of aphasia on bilingualism as measured by differential performance in both languages on the BNT. The BNT is a word retrieval assessment to measure language proficiency in adults who have been diagnosed with aphasia.

Remarkable differences on the BNT were expected between the aphasic and non-aphasic groups and thus, were not analyzed statistically via comparison. To examine the influence of aphasia on bilingualism relative to language proficiency, t-tests were conducted between the scores on the BNT for English and Spanish for the participants within each group (i.e. non-aphasic and aphasic adults analyzed separately). A significant difference was found for the non-aphasic group between English and Spanish scores on the BNT ( $t=2.965615, p<0.02)$. However, there was no significant difference between English and Spanish scores on the BNT for the aphasic group ( $t=0, p>0.05)$. Of particular interest is that although there was no significant difference between the two sets of BNT data for the aphasic participants, this group showed much more variability relative to their performance in English than in Spanish. The t-test data for this analysis is in Appendix D. Figure 7 is a scatter plot display of language proficiency data for both groups with aphasia, as measured via the Boston Naming Test, in both languages. 
Figure 7.Languageproficiency data as measured on the Boston Naming Test for the group withaphasia in bothlanguages.

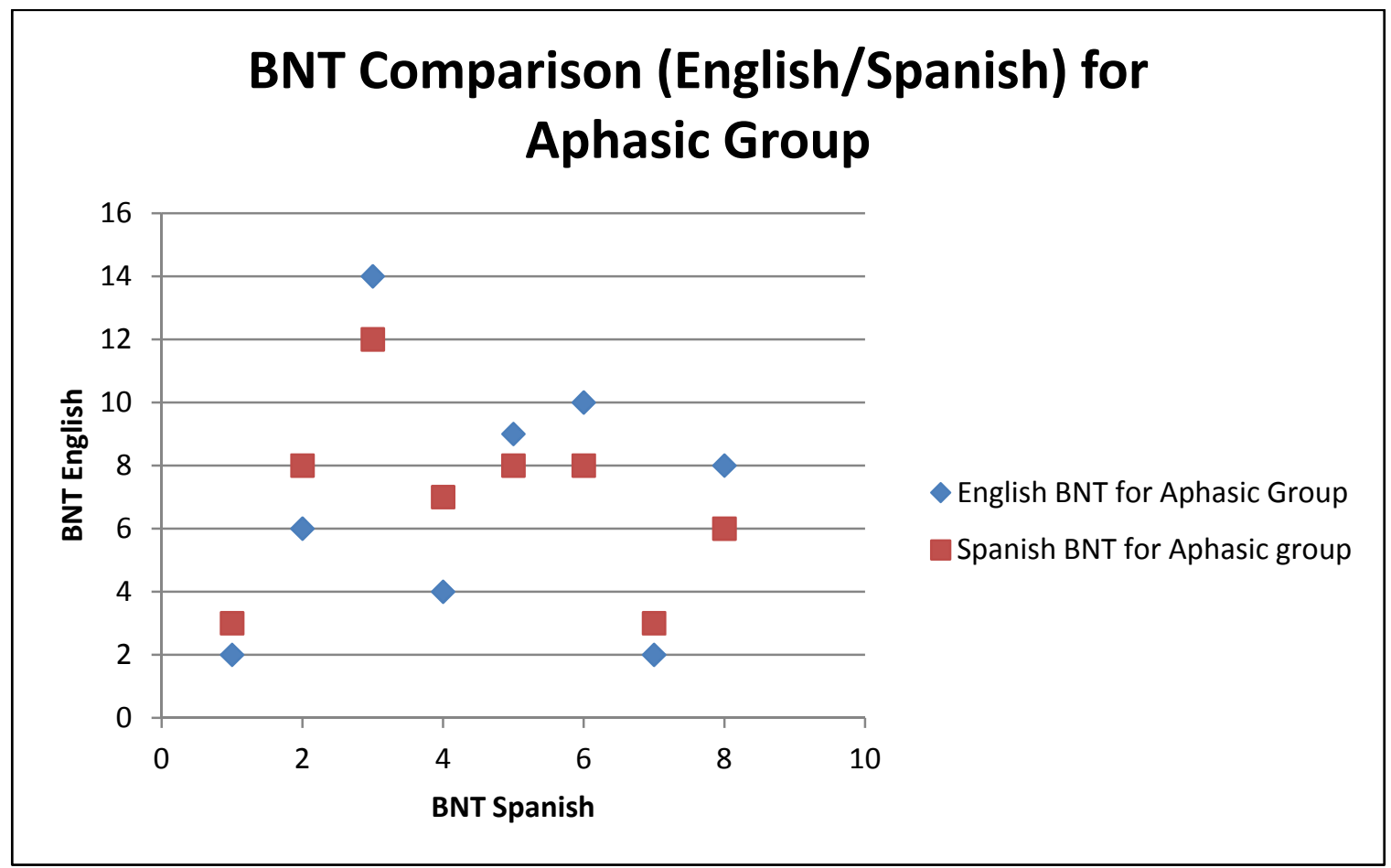

Language Performance in Bilingual Adults with Aphasia

Comparisons also were made between results obtained on the BAT in English and Spanish for the aphasic group. No significant differences were identified when these two data sets were compared ( $t$ value $=0.154042 ; p>0.05$ ). Thus, this result suggests that there is no significant difference between English and Spanish relative to aphasia severity for this sample of aphasic adults. Figure 8 displays the data in scatter plot form for the group with aphasia regarding their severity of language impairment in both languages, as measured via the BAT. Statistical data analysis for the group with aphasia on the BAT in English and Spanish is displayed in Appendix E. 
The last experimental question investigated the relationship between language performance on the BAT and BNT in the bilingual adults with aphasia. Pearson Product Moment correlations were used to examine the relationship between language performance scores on the BAT and BNT in both languages independently. Results for Spanish revealed a strong positive relationship $(r=0.534 ; p<.001)$. The results for English also were strong and positive $(r=0.745 ; p=0.00046)$. Both results indicate statistically significant relationships between language performance on the BAT and BNT in both languages. These findings suggest that language proficiency and severity of impairment in bilingual adults with aphasia are significantly related in both languages, with a stronger relationship in English than Spanish for this sample of adults. BAT and BNT results in English and Spanish are displayed below via scatter plots in Figure 9 and Figure 10, respectively.

Figure 8. English and Spanish Results on the Bilingual Aphasia Test for the group with aphasia.

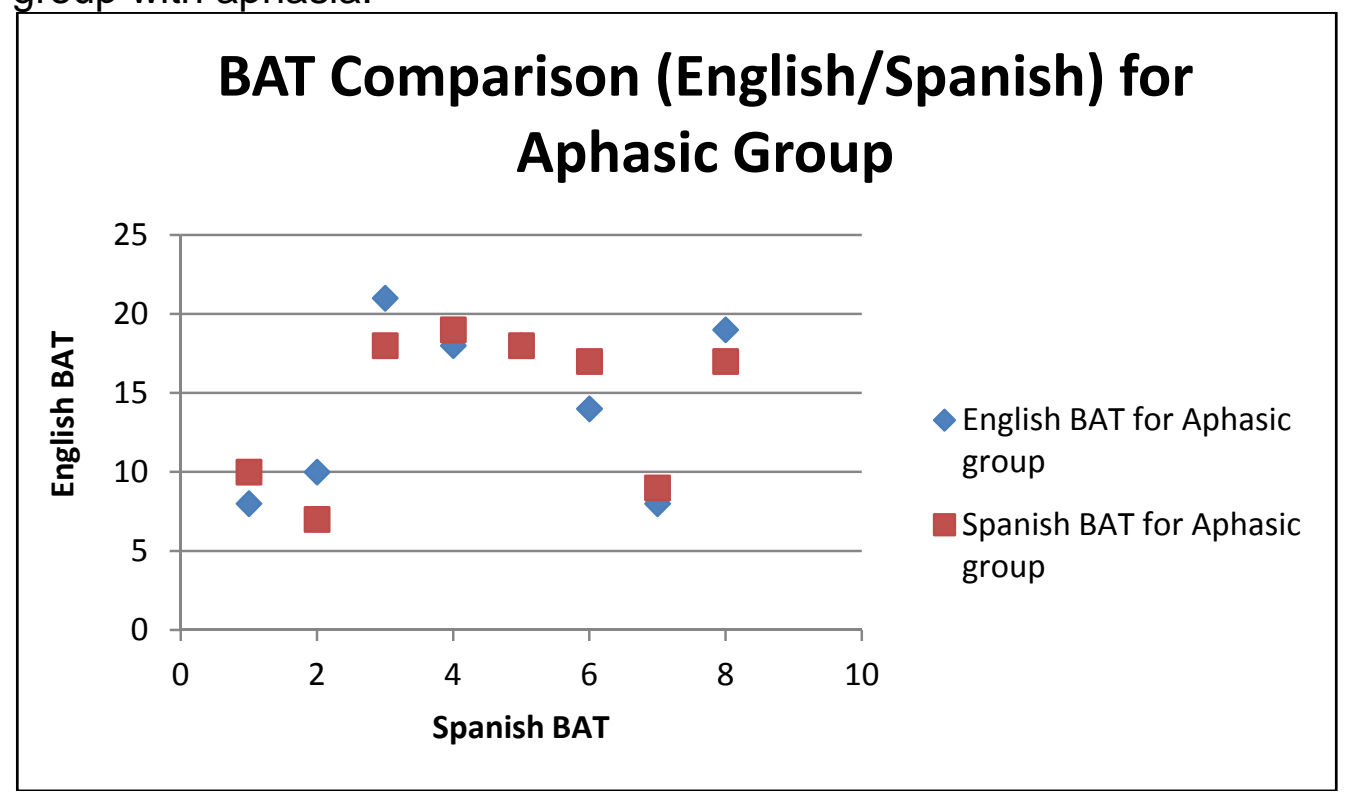


Figure 9. Aphasia severity, as measured by BAT and language proficiency, as measured by BNT in adults with aphasia in English.

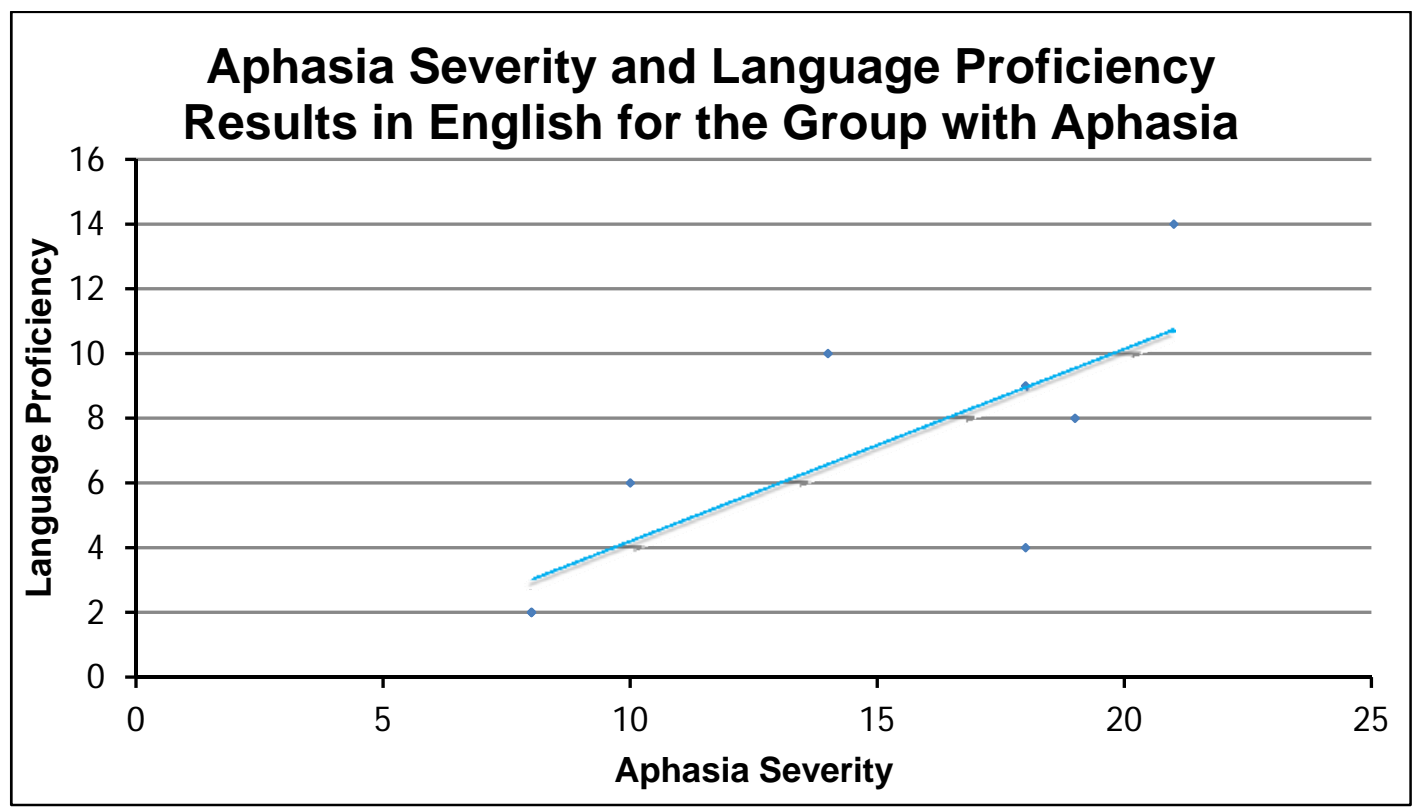

Figure 10. Aphasia severity, as measured by BAT, and language proficiency, as measured by BNT in adults with aphasia in Spanish.

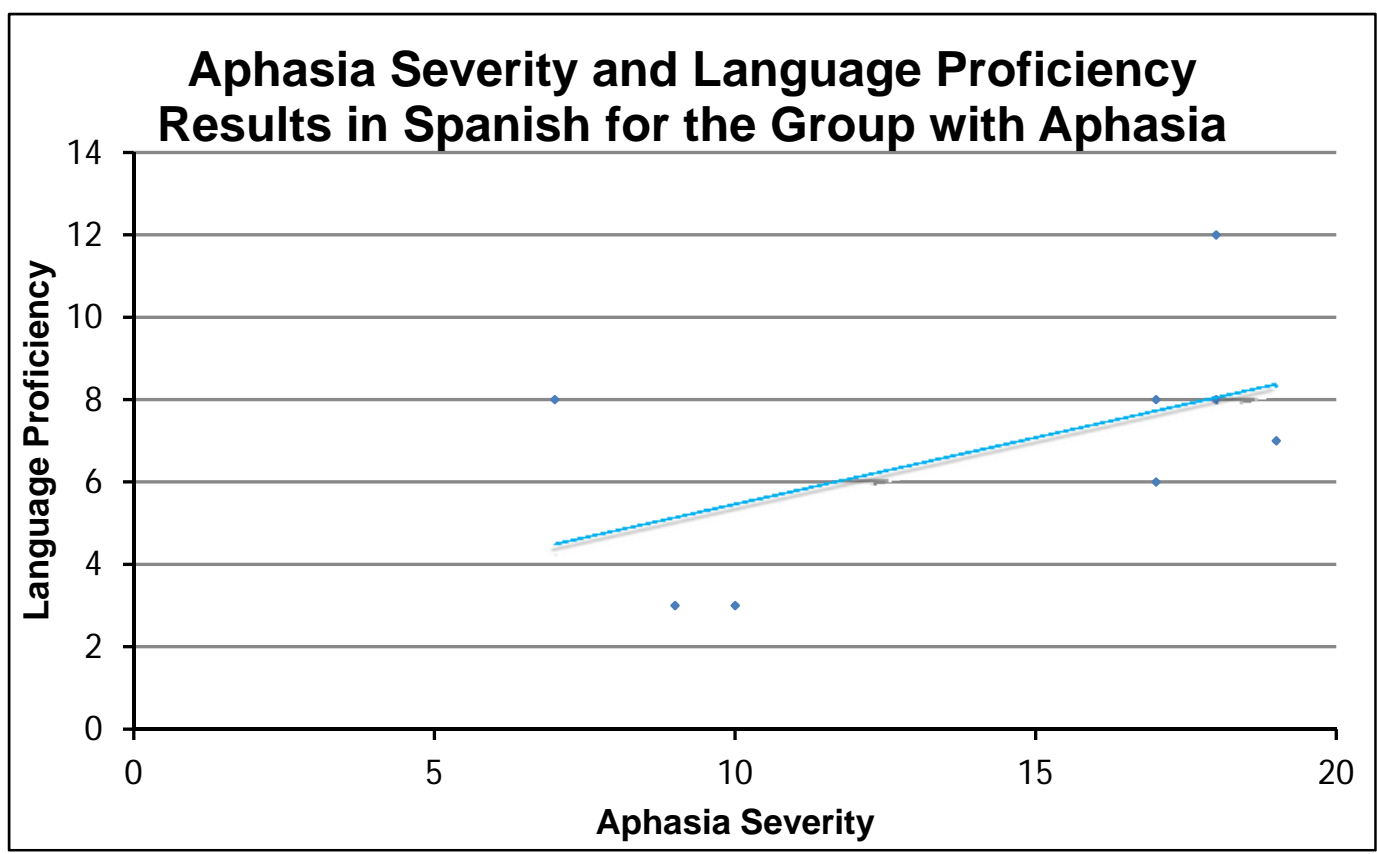


A correlation analysis was completed between aphasia severity, as measured by results on the BAT, and working memory capacity, as measured by results on the listening span task for the group with aphasia. A moderate positive linear relationship was observed between WM and aphasic severity in the group with aphasia in English $(r=0.588396)$. Similar results were obtained for the group with aphasia in Spanish for the relationship between WM and aphasia severity; a moderate positive linear correlation was noted here as well $(r=0.430432)$. These results indicate that working memory capacity and aphasia severity in the group with aphasia are in fact related. Scatter plot representations of the data obtained for results on the BAT and LST in English for the group with aphasia are available in Figure 11; Figure 12 displays that LST and BAT results in Spanish.

Figure 11.LST and BAT Results for the group with Aphasia in English.

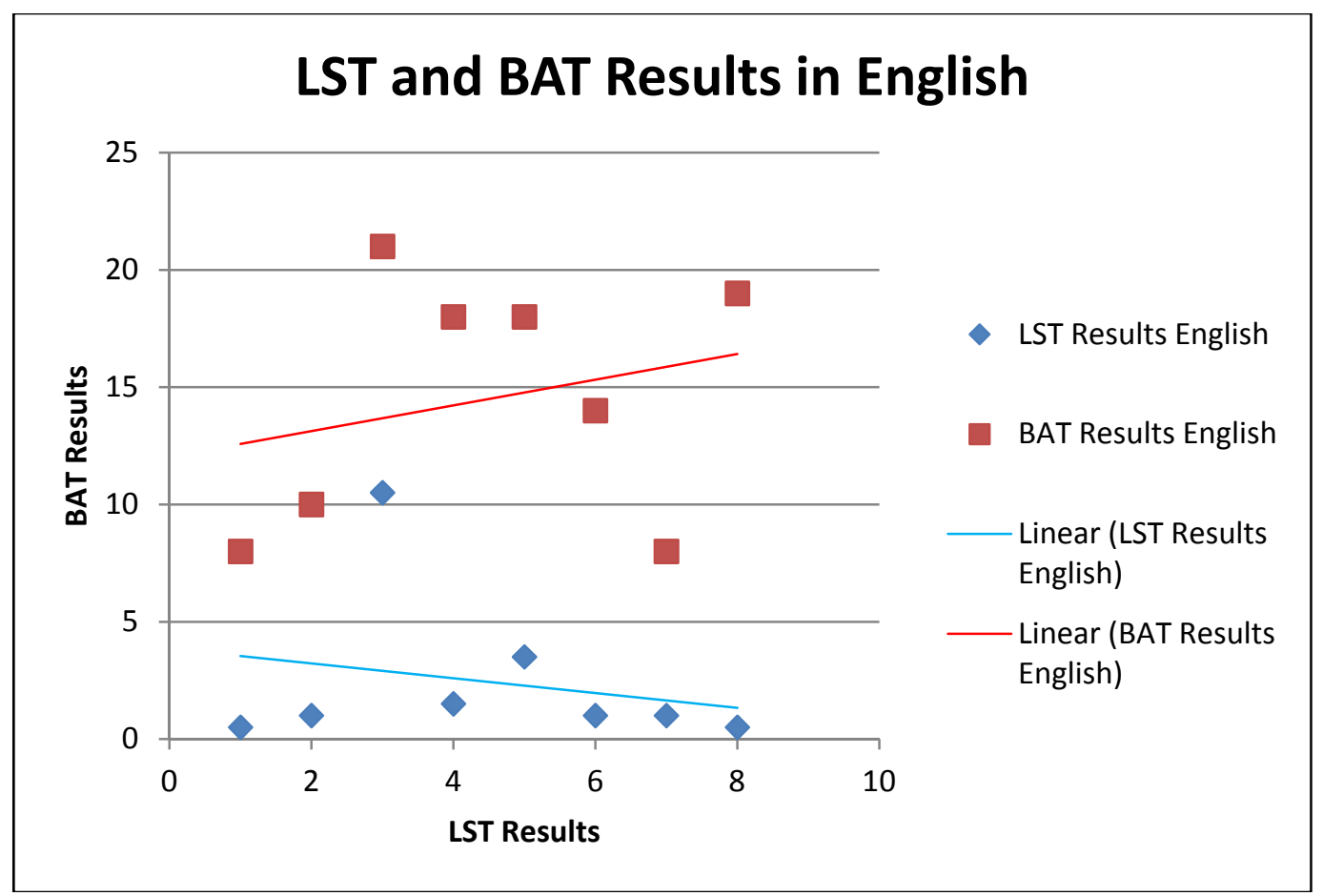


Figure 12.LST and BAT Results for the group with Aphasia in Spanish.

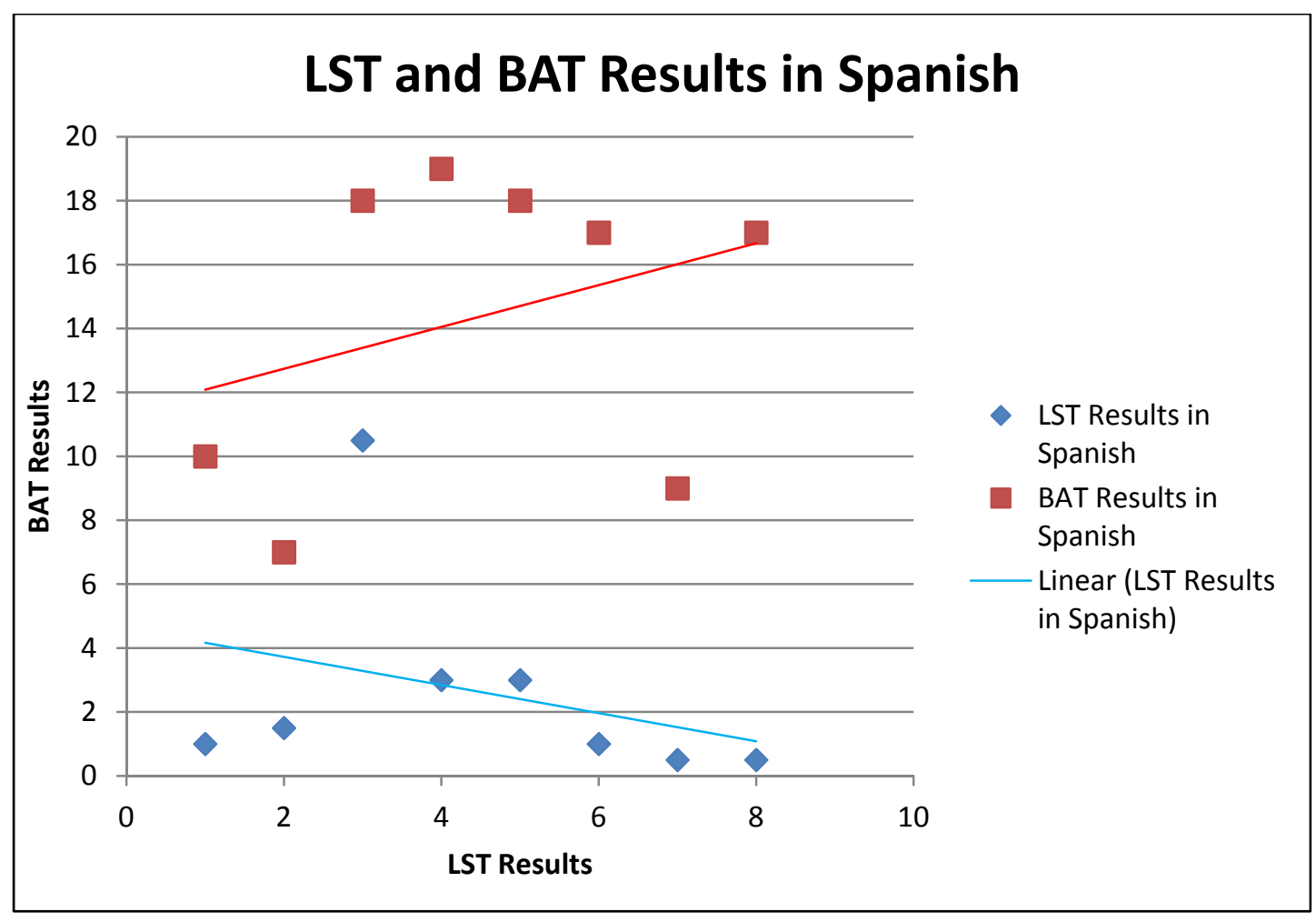




\section{CHAPTER IV}

\section{Discussion}

The purpose of this study was to examine the working memory capacity of bilingual adults with aphasia to non-aphasic bilingual adults in both English and Spanish. A modified version of Daneman and Carpenter's (1980) listening span task was used to examine the working memory capacity of bilingual adults with aphasia to non-aphasic bilingual adults in both English and Spanish. Another purpose of the study was to assess the relationship between working memory as measured by the listening span task with auditory comprehension, as measured via a modified version of the Token Test (De Renzi \& Faglioni, 1978), for both groups in both languages. The impact of bilingualism also was explored relative to language proficiency, as measured by the Boston Naming Test, in both languages for the bilingual adults with and without aphasia.

\section{Aphasia and Working Memory}

The first experimental question addressed the difference in performance between the adults with aphasia compared with the adults without aphasia in working memory as measured via the listening span task in both English and Spanish. Not surprisingly, statistically significant findings were observed when comparing the non-aphasic and aphasic group results for both English and Spanish. Thus, working memory capacity was higher for the non-aphasic group than the aphasic group in both English and Spanish. Current research on aphasia suggests that aphasia is commonly associated with working memory 
deficits (Caspari et al., 1998; Goodglass, Gleeson, \& Hyde, 1970; Gordon, 1983). This hypothesis was the focal point of the study conducted by Caspari et al (1998). In this particular study, a modified version of the Daneman and Carpenter (1980) reading span task was utilized. Strong positive correlations were found between working memory capacity, reading comprehension, and language function. The results of the current study are in agreement with findings of Caspari et al. (1998) and Daneman and Carpenter (1980).

Analysis results revealed no significant differences between English and Spanish for the non-aphasic group on the listening span task. Furthermore, no significant findings were observed for the aphasic group when English and Spanish results were compared. These results suggest that working memory capacity is influenced by the nature of the aphasic linguistic impairment and that bilingualism does not appear to play a significant role in the functioning of working memory for bilingual adults with or without aphasia in these samples of adults. Nonetheless, these findings should be interpreted with caution as a result of the small sample size. It is strongly suggested that bilingual adults with aphasia should be assessed in both languages as the current study did not statistically analyze language acquisition or language dominance (Ardila\& Hough, 2013; Fabbro, 2001; Paradis; 2000).

\section{Working Memory and Auditory Comprehension}

The second experimental question addressed the relationship between WM, as measured by the listening span task and auditory comprehension skills, 
as measured by the Token Test, in both groups in both languages. The strong and positive correlations obtained between listening span and the modified Token Test in both languages for both the non-aphasic and aphasic groups confirms that a remarkable relationship exists between WM and auditory comprehension. As working memory capacities decrease, so does comprehension at the sentence level (Cannito, Hough, Vogel, \& Pierce, 1996). Perhaps of the utmost importance is that the correlations obtained were exactly the same in English and Spanish for the non-aphasic group and nearly identical in the aphasic group in English and Spanish. These results suggest that WM capacity places different constraints on the storage and processing operations involved in language performance, specifically comprehension. The constraints appear to be observed in both English and Spanish for bilingual adults with and without aphasia.

Comprehension deficits observed in the aphasic adults in this study are in congruence with available research. Specifically, it has been proposed that the functionality of WM decreases as auditory comprehension skills decrease and vice versa (Yu, 2010). This notion is based on the work of Just and Carpenter (1992). They concluded that variations in WM capacity may be a result of variations in the available resource pool and/or processing efficiency. The limited resource pool in adults with aphasia suggests that WM deficits are strongly related to deficits in language comprehension and may be the result of reduced ability to store and manipulate information. Burgio and Basso (1996) reached 
similar conclusions. They reported that there is a general impairment in the retention of information specific to adults with aphasia.

Comparisons were conducted between auditory comprehension, as measured via the Token Test, for the group with aphasia in English and Spanish. No significant differences between English and Spanish were observed, suggesting that bilingualism does not influence auditory comprehension in aphasia differently in one language than in another in this sample of adults with aphasia. As WM capacity can be defined as the total amount of resources utilized to support the processing and storage of information (Baddeley, 2003; Caspari et al., 1998; Daneman\& Carpenter, 1980), it has become evident that people utilize a limited resource pool from their WM capacity. This hypothesis may be extended to specify that individuals with aphasia have a WM capacity that is diminished and negatively impacts their level of comprehension (Caspari, 1998). Strong positive correlations in the groups with and without aphasia confirm that WM and comprehension skills are related. The results of this study indicate that this relationship is the similar for bilingual adults in both English and Spanish. Further research is needed in this area.

\section{Aphasia and Bilingualism}

The third experimental question considered the influence of aphasia on bilingualism as measured by differential performance in both languages on the BNT. Interestingly, significant differences were observed between the English and Spanish scores on the language proficiency measure, BNT, for the non- 
aphasic group. Language proficiency in bilingual adults is variable as was found in this study. Types of bilingualism are better described on a continuum where on one side of the continuum some bilinguals have high levels of proficiency in both languages, and on the other side lie adults who possess reduced levels of proficiency in both languages. These variable levels of comprehension and production can be influenced by a variety of factors including: age of $L 2$ acquisition, similarity between L1 and L2, language proficiency, language status, and frequency of use in L1 and L2 (Ardila\& Hough, 2013; Weekes, 2010).

Furthermore, current research suggests that, there are three major distinctions among bilingual adults with regard to language proficiency. The first major distinction is the coordinate bilingual. Coordinate bilingualism is comprised of two lexical and two semantic systems. This theory suggests that coordinate bilinguals acquire the two languages in different contexts, thus indicating that the two languages belong to independent systems. The next distinction is called compound bilingualism. Compound bilingualism suggests the presence of two lexical systems and one semantic system. This distinction implies that a bilingual person acquires two words for one concept. The final distinction is called subordinate bilingualism. In this distinction, there is one semantic system and two lexical systems. Subordinate bilingualism exists when language elements of a person's language are only available through elements of the other language (Ardila\& Hough, 2013). Although findings on language proficiency of the nonaphasic bilingual adults does not concur with other findings, significant differences found on the BNT between English and Spanish for this group may 
be attributed to the different forms of language proficiency acquired by a bilingual adult.

Comparison of results on the BNT between English and Spanish performance did not result in significant differences for the group with aphasia. It appears that bilingual aphasic adults are impaired in very distinct ways and to varying same degrees in both languages. Furthermore, there are large variations with regards to recovery patterns in bilingual adults with aphasia as well. Thus, it is widely suggested that assessments for bilingual adults with aphasia be conducted in both languages (Ardila\& Hough, 2013; Fabbro, 2001; Paradis; 2000). Results of this study suggest otherwise. No remarkable difference was observed in either language suggesting that assessments can thus be administered in either language and be noted as a reliable source of information during the assessment intervention. Results of this study should be interpreted with caution as a result of the small sample size.

\section{English and Spanish Comparison in the Group with Aphasia on the BAT}

No significant differences between English and Spanish were identified on the BAT used to assess aphasia severity in the group with aphasia. As a result, these findings suggest the idea that bilingual adults with aphasia do not display remarkable differences with regard to their deficits in either language. Recovery patterns are currently believed to be either parallel (where both languages recover simultaneously) or dissociated (where the pattern of recovery is different for each language) in bilingual adults with aphasia (Ardila\& Hough, 2013; Fabbro, 
2001). Furthermore, the current consensus is that language recovers the best in bilingual adults with aphasia is the mother languageby Ribot (1883) (as cited in Ardila\& Hough, 2013). Similarly, Pitre (1895) suggested that the language that recovers the best is the language that was most consistently used prior to the onset of the brain damage (as cited in Ardila\& Hough, 2013). Results of this study may contradict these theories. However, no significant differences on the BAT in English and Spanish are believed to be a result of semantically and grammatically equivalent translations readily available for the BAT.

\section{Language Performance in Bilingual Adults with Aphasia}

The final experimental question addressed the relationship between language performance on the BAT and BNT in the bilingual adults with aphasia. Strong positive correlations were observed for results in both English and Spanish, thus suggesting a strong relationship between aphasia severity and language proficiency in this sample of aphasic adults. The subsystem hypothesis by Paradis (2000) suggests that there is one main language system in bilinguals as there is in monolinguals. However, in bilinguals, this main language system (language spoken more often) is then subdivided into smaller systems based on the number of languages a person speaks. The main language system is susceptible to pathology just as each individual subsystem. The Subsystem Hypothesis suggests that although all languages used by one person have the same probability of experiencing deficits post-aphasia, recovery patterns for the main system and corresponding subsystems can vary greatly as a result of many 
influential factors (age of acquisition, language proficiency, language status, as well as frequency of use in L1 and L2).

\section{Limitations of Current Research}

Several limitations of this study were identified during its progression. One limitation of the current research was that time post-onset of neurological damage resulting in aphasia was noted but not controlled. Furthermore, the current sample size for both groups was small. Another limitation was not including monolingual adults for both groups. Because of limited participant availability and definitive published research with monolingual speakers relative to WM for both samples, these possible participants were not included in the study. However, addressing these factors, particularly the latter issue in future research, would allow for tighter control of extraneous variables and more valid observations.

Implications for Further Research

First, additional research should focus on the particular relationship of processing and storage and its impact on auditory comprehension. Time allotted for participants to process and store information was controlled at 10 seconds. Random and variable time to complete WM tasks paired with comprehension tasks may provide data that would allow analysis of differences in processing and storage available in different groups. Such research may shed light on the manner in which the two components of working memory, process and storage, 
are related and if the working memory system is impacted via the processing component, the storage component or both when auditory comprehension deficits are apparent in aphasia. A second factor to consider with the aphasic group is sentence structure. The impact of syntax on comprehension skills in adults with aphasia has long been debated. Though somewhat controlled in this study, variable sentence structure in English and Spanish could have influenced the outcome of WM and auditory comprehension measures because one language is perceived to be more complex. Thus, further research should attempt to match sentence structure as closely as possible.

With the growing bilingual population in the United States, it is essential that future studies on the effects of bilingual aphasia provide novel information on the structure and functioning of the bilingual language system as well as evidence for or against the available models of bilingual language processing, particularly in working memory (Kiran\& Roberts, 2010). This may be accomplished via replication of this study with larger groups of bilingual adults as well as more comprehensive measures of language proficiency such as Woodcock-Munoz Language Survey-Revised or the Bilingual Vocabulary Assessment Measure and aphasia severity measures such as the Multilingual Aphasia Examination (MAE), Cognitive Linguistic Quick Test, or the Bilingual Verbal Ability Test (BVAT). Results using a variety of assessment measures may help provide more evidence for the inter-relationships between language proficiency, WM, and auditory comprehension. Speech language pathologists specifically, should acknowledge the relationships between working memory and 
31aphasia severity, and the impact that bilingualism can have on both of these skills. Overall, the current research further supports the notion that both assessments and treatments provided to bilingual adults should be administered in both languages to obtain an in depth analysis of the individuals language profile especially with regards to working memory.

\section{Summary and Conclusions}

The purpose of the current study was to explore the effects of aphasia on working memory in bilingual adults. The results revealed that working memory capacity, as measured by the listening span task, was significantly higher for the non-aphasic group than the aphasic group in both English and Spanish. Results for both groups yielded relatively equivalent findings for the two languages on the working memory measures. Highly significant and strong positive correlations were identified between working memory and auditory comprehension for both groups in English and Spanish. However, there were no significant differences between English and Spanish results relative to auditory comprehension in the group with aphasia.

Regarding language proficiency, it was interesting to observe no significant differences between English and Spanish scores for the group with aphasia on the BNT. There was, however, notably more variability for English than Spanish on the BNT for the aphasic participants. Just as interesting was the finding of a significant difference between English and Spanish on the language proficiency measure (BNT) for the non-aphasic group. 
With regard to aphasia severity, no significant differences were found between English and Spanish on the BAT. However, moderate to strong positive linear relationships were observed between working memory and aphasic severity for the group with aphasia in both languages. Furthermore, strong positive relationships were found between language proficiency and aphasia severity in both languages.

In conclusion, results suggest that the impact of bilingualism on working memory for aphasic adults may be similar to what has been observed for monolingual aphasic individuals. Specifically, research for monolingual speakers has revealed strong relationships between auditory comprehension and working memory capacity. In the current study, highly significant and strong positive correlations were identified between working memory and auditory comprehension for aphasic and non-aphasic adults in both English and Spanish.

It is also important to note that variable levels of language proficiency are found in bilingual adults. Evaluation and treatment of bilingual adults should be completed with particular attention to language proficiency for both the English and Spanish languages, language acquisition, and language dominance. Not only should these factors be analyzed thoroughly in non-aphasic bilingual individuals, but also in bilingual adults with aphasia along with their variable recovery patterns. Intervention should be individualized and focused on the functional communication needs of the patient given their specific language 
profile. As a whole, further research is still needed in the area of working memory and its influential effects on linguistic functioning in bilingual adults. 


\section{LIST OF REFERENCES}

Achim, A Marquis (2011). An automated version of the BAT Syntactic Comprehension task for assessing auditory L2 proficiency in healthy adults.Clinical linguistics \& phonetics 25 (6-7), 655-669.

American Speech-Language Hearing Association Audiologic Assessment Panel 1996.(1997). Guidelines for audiologic screening. Rockville, MD

Ardila, A. (2003). Language representation and working memory with bilinguals. Journal of Communication Disorders, 36, 233-240.

Ardila, A. \& Hough, M. (2013).Aphasia. Miami, FL: Florida International Univeristy.

Atkins, P.W.B., Baddeley, A.D. (1998) Working memory and distributed vocabulary learning. Applied Psycholinguistics, 19, 537-552.

Baddeley, A., Wilson, B. \& Watts, F. (Eds.) (1995) Handbook of Memory Disorders. Chichester, W.Sussex: John Wiley \& Sons Ltd.

Baddeley, A.D. (2003). Working memory and language: an overview. Journal of Communication Disorders, 36, 189-208. Retrieved from

http://www.sciencedirect.com/science/article/pii/S0021992403000194

Berthier, M. (1999).Transcortical aphasias. East Sussex: Psychology Press.

Brodsky, M.B., McNeil, M.R., Doyle, P.J., Fossett, T.R.D., Timm, N.H., \& Park, G.H. (2003) Auditory serial position effects in story retelling for non-brain-injured participants and persons with aphasia. Journal of Speech, Language, and Hearing Research, 46, 1124-1137.

Burgio, F., Basso, A. (1996).Memory and aphasia.Neuropsychologia.35, 759766.

Cannito, M. P., Hough, M., Vogel, D., \& Pierce, R.S. (1996). Contextual influences on auditory comprehension of reversible passive sentences in aphasia. Aphasiology, 10, 235-251.

Caramazza, A. (1988). Some aspects of language processing revealed through the analysis of acquired aphasia: The lexical system. Ann. Rev. Neurosci, 11, 395-421.

Caspari, I., Parkinson, S.R., LaPointe, L.L., \& Katz, R.C. (1998).Working memory and aphasia. Brain and Cognition, 37, 205-223. 
Daneman, M., \& Carpenter, P. (1980).Individual differences in working memory and reading. Journal of Verbal Learning and Verbal Behavior, 19, 450-466.

Darley, F. L. (1982). Aphasia. Philidelphia: W.B. Saunders.

Davis, G. A. (2007). Aphasiology: Disorders and clinical practice. Boston: Allyn and Bacon.

de Bot, K. (1992) A bilingual production model: Levelt's Speaking model adapted. 562. Applied Linguistics 13 (1), 1-24.

De Renzi, E. \& Faglioni, P., (1978).Normative data and screening power of a shortened version of the token test.Cortex,14, 49-49.

Edmonds, L. A. \&Kiran, S. (2006). Effect of semantic naming treatment on crosslinguistic generalization in bilingual aphasia. Journal of Speech, Language, and Hearing Research, 49, 729-748.

Fabbro, F. (2001). The bilingual brain: Bilingual aphasia. Brain and Language, 79, 201-210.

Friedmann, N., Gvion, A. (2003). Sentence comprehension and working memory limitation in aphasia: A dissociation between semantic-syntactic and phonological reactivation. Brain and Language, 86, 23-29.

Goodglass, H., Gleason, J. Berko, and Hyde, M. (1970). Some dimensions of auditory language comprehension in aphasia. Journal of Speech and Hearing Research, 13, 96-606. (Editor's Award)

Kaplan, E., Goodglass, H., \&Weintraub, S. (1983). Boston Naming Test. Phiidelphia. Lea \& Febiger.

Green, D.W. (1986). Control, activation, and resource: A framework and a model for the control of speech in bilinguals. Brain Language, 27, 210-223.

Gordon, W.P. (1983). Memory disorders in aphasia-auditory immediate recall. Neuropyschologia, 21, 325-339.

Gutbrod, K., Cohen, R., Maier, T., Meier, E. (1987). Memory for spatial and temportal order in aphasics and right hemisphere damaged patients. Cortex, 23, 463-474.

Haarmann, H.J., Just, M. A., \& Carpenter, P.A. (1997). Aphasic sentence comprehension as a resource deficit: a computational approach. Brain and Language, 59, 76-120.

Hitch, G.J., Baddeley, A.D. (1974).Verbal reasoning and working memory.Quarterly Journal of Experimental Psychological, 28, (4), 603-621. 
Kiran, S. \& Roberts, P. M. (2010).Semantic feature analysis treatment in spanishenglish and french-english bilingual aphasia. Aphasiology, 24, 231-261.

Kucera, H., \& Francis, W.N. (1967).Computational analysis of present-day American English. Providence, RI: Brown University Press.

LaPointe, L.L., \& Engle R. W. (1990). Simple and complex word spans as measures of working memory capacity. Journal of Experimental Psychology; Learning, Memory, and Cognition, 16, 1118-1133.

Martin, N., Reilly, J. (2012). Short-term/working memory impairments in aphasia: Data, models and their application to aphasia rehabilitation. Aphasiology, 26, 253-257.

Martin, N. \&Saffran, E.M. (1997). Language and auditory-verbal short-term memory impairments: Evidence for common underlying processes. Cognitive Neuropsychology, 14, 641-682.

Martin, N., Saffran, E. M., \& Dell, G.S. (1996).Recovery in deep dysphasia: evidence for a relation between auditory-verbal stm capacity and lexical errors in repetition. Brain and Language, 52, 83-113.

MedicineNet.com. Retrieved 10/1/2013 from: http://www.medterms.com/script/main/art.asp?articlekey $=7143$

Paradis, M. (1993) Foundations of Aphasia Rehabilitation. Oxford, Pergamon Press.

Paradis, M. (2000).Generalizable outcomes of bilingual aphasia research. Folia Phoniatricaet Logopaedica, 52, 54-64.

Pierce, R.S., \&DeStefano, C.C. (1987). The interactive nature of auditory comprehension in aphasia. Journal of Communication Disorders, 20, 15-24.

Shin, H. B., Kominski, R.A. (2010) Language use in the United States: 2007. American Community Survey Reports-12. Retrieved from www.census.gov/prod/2010pubs/acs-12.pdf

Weekes, B. S. (2010). Issues in bilingual aphasia: an introduction. Aphasiology, 24 (2), 123-125.

$\mathrm{Yu}, \mathrm{K}$. (2010). Influence of linguistic context and working memory on auditory comprehension in young and older adults with aphasia (Master's Thesis). East Carolina University, Greenville, NC.

Zurif, E.B., Caramazza, A., Foldi, N.S., \& Gardner, H. (1979).Lexical semantics and memory for words. Journal of Speech and Hearing Research, 22, 456-467. 


\begin{tabular}{|l|l|}
\hline FIU IRB Approval: & $2 / 18 / 2014$ \\
\hline FIU IRB Expiration: & $2 / 18 / 2015$ \\
\hline FIU IRB Number: & IRB-13-0624 \\
\hline
\end{tabular}

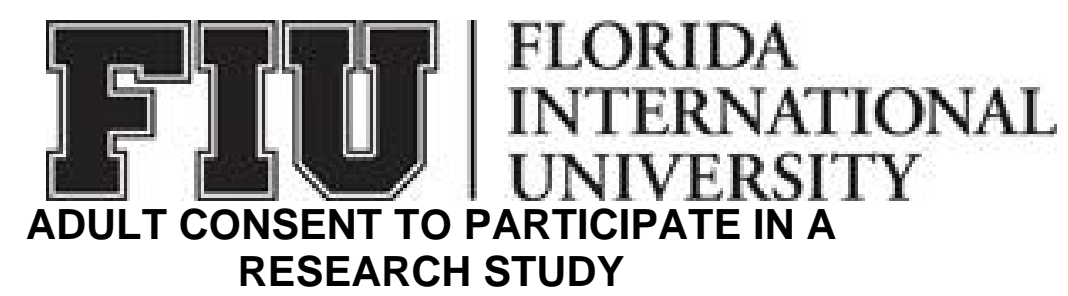

The Impact of Aphasia on Working Memory in Bilingual Adults

\section{PURPOSE OFTHE STUDY}

You are being asked to be in a research study. The purpose of this study is to investigate the effect of aphasia on a series of working memory tasks in bilingual adults.

\section{NUMBER OFSTUDYPARTICIPANTS}

If you decide to be in this study, you will be one of sixteen (16) people in this research study.

\section{DURATION OFTHESTUDY}

Your participation will require 1-2 hours over 1-2sessions within the same week.

\section{PROCEDURES}

If you agree to be in the study, we will ask you to do the following things:

1. Participants will be administered a hearing screening prior to any assessment to ensure that results are not impacted by the extraneous variable of hearing loss.

2. The Token Test will be administered to both the experimental group and control groups. The Token Test requires participants to follow simple 1, 2, and 3 step directions regarding identification and adjustment of tokens on a color coded placement card.

3. The Bilingual Aphasia Test (BAT) will be administered to the group with aphasia The BAT consists of the following. The BAT is comprised of three major parts: 1. A question/answer portion to obtain the participant's history of bilingualism, 2. the participants language background and spontaneous language productions, and 3. Four tasks administered in each direction (translation fromL1 toL2 and translation fromL2 toL1). These tasks include: auditory comprehension, syntax comprehension, categorical semantics, and grammatical tasks.

Page 1 of 3 


\begin{tabular}{|l|l|}
\hline FIU IRB Approval: & $2 / 18 / 2014$ \\
\hline FIU IRB Expiration: & $2 / 18 / 2015$ \\
\hline FIU IRB Number: & IRB-13-0624 \\
\hline
\end{tabular}

4. The final task will be a listening span task. The participant will be asked to recall sentences that are approximately five to six words in length as well as a word that is to be recalled after the end of each sentence, called the terminal word. The information will be presented both visually and orally. After reading the sentences the participant will be asked to recognize the word that was presented right after the sentence by pointing to a corresponding picture. Participants will be assessed in both their first and second languages. Audio, video, or image recording, observation, as well as educational tests will be utilized during all of the above mentioned participant tasks.

\section{RISKSANDIOR DISCOMFORTS}

The following risks maybe associated with your participation in this study: First, psychological risks, thought to be extremely minimal, would consist of discomfort when presented with difficult or unfamiliar tests materials. To minimize this risk, participants will continually be encouraged throughout the duration of the research study and will not be presented with any judgment or ridicule.

\section{BENEFITS}

The following benefits may be associated with your participation in this study: an increase in the understanding of the correlation between aphasia recovery and working memory in bilingual adults as well as additional information on useful intervention approaches that may be beneficial to members of the community.

\section{ALTERNATIVES}

There are no known alternatives available to you other than not taking part in this study. However, any significant new findings developed during the course of the research which may relate to your willingness to continue participation will be provided to you.

\section{CONFIDENTIALITY}

The records of this study will be kept private and will be protected to the fullest extent provided by law. In any sort of report we might publish, we will not include any information that will make it possible to identify a subject. Research records will be stored securely and only the researcher team will have access to the records. However, your records maybe reviewed for audit purposes by authorized University or other agents who will be bound by the same provisions of confidentiality.

\section{COMPENSATION\&COSTS}

Participants will not receive any monetary compensation for participation in this research study. You will not be responsible for any costs to participate in this study.

Page 2 of 3 


\section{MEDICAL TREATMENT}

\begin{tabular}{|l|l|}
\hline FIU IRB Approval: & $2 / 18 / 2014$ \\
\hline FIU IRB Expiration: & $2 / 18 / 2015$ \\
\hline FIU IRB Number: & IRB-13-0624 \\
\hline
\end{tabular}

Routinely, FIU, its agents, or its employees do not compensate for or provide free care for human subjects in the event that any injury results from participation in a research project. If you become ill or injured as a direct result of participating in this study, contact your regular medical provider. If you have insurance, your insurance company may or may not pay for these costs. If you do not have insurance, or if your insurance company refuses to pay, you will be billed. Funds to compensate for pain, expenses, lost wages and other damages caused by injury are not routinely available.

\section{RIGHTTO DECLINE OR WITHDRAW}

Your participation in this study is voluntary. You are free to participate in the study or withdraw your consent at any time during the study. Your withdrawal or lack of participation will not affect any benefits to which you are otherwise entitled. The investigator reserves the right to remove you without your consent at such time that they feel it is in the best interest.

\section{RESEARCHER CONTACT INFORMATION}

If you have any questions about the purpose, procedures, or any other issues relating to this research study you may contact Monica Hough at,11200 S.W. ${ }^{\text {th }}$ Street, 305-348-2873, mshough@fiu.eduor Giselle

Ogrodnik at 11200 S.W. 8 Street, 786-663-5638,gogro001@fiu.edu.

\section{IRB CONTACT INFORMATION}

If you would like to talk with someone about your rights of being a subject tin this research study or about ethical issues with this research study, you may contact the FIU Office of Research Integrity by phone at 305-348-2494 or by email at ori@fiu.edu.

\section{PARTICIPANT AGREEMENT}

I have read the information in this consent form and agree to participate in this study. I have had a chance to ask any questions I have about this study, and they have been answered for me. I understand that I am entitled to a copy of this form after it has been read and signed.

Signature of Participant

Date

Printed Name of Participant

Signature of Person Obtaining Consent

Date

Page 3 of 3 
Appendix B. Data Collection Sheet

\begin{tabular}{|c|c|c|c|c|c|c|c|c|c|}
\hline \multicolumn{10}{|c|}{$\begin{array}{l}\text { Data Collection Sheet } \\
\text { Non-Aphasic Group }\end{array}$} \\
\hline $\begin{array}{c}\text { Partici } \\
\text { pant } \\
\text { Numbe } \\
r\end{array}$ & $\begin{array}{c}\text { Au } \\
\text { dio } \\
\text { (pa } \\
\text { ssl } \\
\text { fail) }\end{array}$ & $\begin{array}{c}\text { Toke } \\
\text { n } \\
\text { Test } \\
\text { Engli } \\
\text { sh }\end{array}$ & $\begin{array}{c}\text { Toke } \\
\text { n } \\
\text { Test } \\
\text { Spani } \\
\text { sh }\end{array}$ & $\begin{array}{c}\text { BAT } \\
\text { Engli } \\
\text { sh }\end{array}$ & $\begin{array}{c}\text { BAT } \\
\text { Span } \\
\text { sh }\end{array}$ & $\begin{array}{c}\text { BNT } \\
\text { Engli } \\
\text { sh }\end{array}$ & $\begin{array}{c}\text { BNT } \\
\text { Spani } \\
\text { sh }\end{array}$ & $\begin{array}{c}\text { LST } \\
\text { Englis } \\
\text { h }\end{array}$ & $\begin{array}{c}\text { LST } \\
\text { Spanis } \\
\mathrm{h}\end{array}$ \\
\hline \multicolumn{10}{|l|}{1} \\
\hline \multicolumn{10}{|l|}{2} \\
\hline \multicolumn{10}{|l|}{3} \\
\hline \multicolumn{10}{|l|}{4} \\
\hline \multicolumn{10}{|l|}{5} \\
\hline \multicolumn{10}{|l|}{6} \\
\hline \multicolumn{10}{|l|}{7} \\
\hline \multicolumn{10}{|l|}{8} \\
\hline \multicolumn{10}{|l|}{ Mean } \\
\hline \multicolumn{10}{|l|}{ SD } \\
\hline \multicolumn{10}{|c|}{ Aphasic Participants } \\
\hline \multicolumn{10}{|l|}{9} \\
\hline \multicolumn{10}{|l|}{10} \\
\hline \multicolumn{10}{|l|}{11} \\
\hline \multicolumn{10}{|l|}{12} \\
\hline \multicolumn{10}{|l|}{13} \\
\hline \multicolumn{10}{|l|}{14} \\
\hline \multicolumn{10}{|l|}{15} \\
\hline \multicolumn{10}{|l|}{16} \\
\hline \multicolumn{10}{|l|}{ Mean } \\
\hline SD & & & & & & & & & \\
\hline
\end{tabular}




\section{Appendix C.}

Pearson product moment correlations for auditory comprehension and working memory in aphasic and non-aphasic participants in English and Spanish.

\begin{tabular}{|c|c|c|}
\hline \multicolumn{2}{|c|}{ Non-aphasic Participants } & \\
\hline & Auditory Comprehension & \\
\hline \multirow{2}{*}{$\begin{array}{l}\text { Working } \\
\text { Memory }\end{array}$} & $r$ value $=1$ & $\begin{array}{l}\quad \text { Legend: } \\
\text { Red r value= } \\
\text { English }\end{array}$ \\
\hline & r value $=1$ & $\begin{array}{l}\text { Blue } r \text { value= } \\
\text { Spanish }\end{array}$ \\
\hline \multicolumn{2}{|c|}{ Aphasic Participants } & \\
\hline & Auditory Comprehension & \\
\hline \multirow{2}{*}{$\begin{array}{l}\text { Working } \\
\text { Memory }\end{array}$} & r value: 0.775863 & \\
\hline & r value: 0.776423 & \\
\hline
\end{tabular}


Appendix D. Data Analysis for the Non-aphasic and Aphasia Group on the BNT in English and Spanish.

Data Analysis for the Non-aphasic Group on the BNT in English and Spanish.

\begin{tabular}{|l|r|r|}
\hline \multicolumn{3}{|c|}{ t-Test: Paired Two Sample for Means } \\
\hline & $\begin{array}{c}\text { Variable } \\
1\end{array}$ & Variable 2 \\
\hline Mean & 13.25 & 12.375 \\
\hline Variance & 1.071429 & 0.553571429 \\
\hline Observations & 8 & \\
\hline Pearson Correlation & 0.602861 & \\
\hline Hypothesized Mean Difference & 0 & \\
\hline Df & 7 & \\
\hline$t$ Stat & 2.965615 & \\
\hline$P(T<=t)$ one-tail & 0.010469 & \\
\hline$t$ Critical one-tail & 1.894579 & \\
\hline$P(T<=t)$ two-tail & 0.020938 & \\
\hline$t$ Critical two-tail & 2.364624 & \\
\hline
\end{tabular}


Data Analysis for the Aphasic Group on the BNT in English and Spanish.

\begin{tabular}{|l|r|r|}
\hline \multicolumn{3}{|c|}{ t-Test: Paired Two Sample for Means } \\
\hline & $\begin{array}{c}\text { Variable } \\
1\end{array}$ & Variable 2 \\
\hline Mean & 6.875 & 6.875 \\
\hline Variance & 17.55357 & 8.696428571 \\
\hline Observations & 8 & \\
\hline Pearson Correlation & 0.900423 & \\
\hline Hypothesized Mean Difference & 0 & \\
\hline Df & 7 & \\
\hline t Stat & 0 & \\
\hline$P(T<=t)$ one-tail & 0.5 & \\
\hline$t$ Critical one-tail & 1.894579 & \\
\hline$P(T<=t)$ two-tail & 1 & \\
\hline$t$ Critical two-tail & 2.364624 & \\
\hline
\end{tabular}


Appendix E. Data Analysis for the Group with Aphasia on the BAT in English and Spanish.

\begin{tabular}{|l|r|r|}
\hline \multicolumn{3}{|c|}{ t-Test: Paired Two Sample for Means } \\
\hline & $\begin{array}{c}\text { Variable } \\
1\end{array}$ & Variable 2 \\
\hline Mean & 14.5 & 14.375 \\
\hline Variance & 27.42857 & 23.41071429 \\
\hline Observations & 8 & \\
\hline Pearson Correlation & 0.899195 & \\
\hline Hypothesized Mean Difference & 0 & \\
\hline df & 7 & \\
\hline$t$ Stat & 0.154042 & \\
\hline$P(T<=t)$ one-tail & 0.440962 & \\
\hline$t$ Critical one-tail & 1.894579 & \\
\hline$P(T<=t)$ two-tail & 0.881924 & \\
\hline$t$ Critical two-tail & 2.364624 & \\
\hline
\end{tabular}


Appendix G. Sentence and Terminal Word Stimulus for the Listening Span Task in English

\begin{tabular}{|l|l|l|}
\hline \multicolumn{2}{|c|}{ Module 1 English } \\
\hline & Sentences & Terminal Word \\
\hline Trial 1 & The man will drive. & book \\
\hline Trial 2 & The girl can sing. & ant \\
\hline Trial 3 & It has been good. & saw \\
\hline Trial 4 & There are two shoes. & kite \\
\hline Trial 5 & She ate an apple. & mask \\
\hline
\end{tabular}

\begin{tabular}{|l|l|l|}
\hline \multicolumn{2}{|c}{ Module 2 English } \\
\hline & Sentences & Terminal Word \\
\hline Trial 1 & That car is red. & dog \\
\hline Trial 2 & Ice can be cold. & bed \\
\hline Trial 3 & The dark corner. & egg \\
\hline Trial 4 & There are fish in that lake. & baby \\
\hline Trial 5 & Give him a chance. & rag \\
\hline Trial 6 & Take it out of the basket. & zoo \\
\hline Trial 7 & I eat a lot of cake. & lamp \\
\hline Trial 8 & She has long hair. & bug \\
\hline Trial 9 & Just kiss the boy. & net \\
\hline Trial 10 & I live on a farm. & can \\
\hline
\end{tabular}




\begin{tabular}{|l|l|l|}
\hline \multicolumn{2}{|c|}{ Module 3 English } \\
\hline & Sentences & Terminal Word \\
\hline Trial 1 & That is the law. & Drink \\
\hline Trial 2 & She is local. & Arm \\
\hline Trial 3 & The plane is in the air. & Ten \\
\hline Trial 4 & There are two blue eyes. & Street \\
\hline Trial 5 & Give her some help. & Feet \\
\hline Trial 6 & The news is public. & Desk \\
\hline Trial 7 & I am going to the city. & Coke \\
\hline Trial 8 & The kid is in the room. & Milk \\
\hline Trial 9 & That does not make sense. & Tape \\
\hline Trial 10 & She sat on the chair. & Heart \\
\hline Trial 11 & Last night was fun. & Shark \\
\hline Trial 12 & That is our history. & Tooth \\
\hline Trial 13 & Write above the line. & Fire \\
\hline Trial 14 & Clean both of your hands. & Gun \\
\hline Trial 15 & It is time for school. & World \\
\hline
\end{tabular}




\begin{tabular}{|l|l|l|}
\hline \multicolumn{2}{|c|}{ Module 4 English } \\
\hline & Sentences & Terminal Word \\
\hline Trial 1 & We play many games. & Neck \\
\hline Trial 2 & There has been a lot of growth. & Black \\
\hline Trial 3 & The bill is paid. & Stage \\
\hline Trial 4 & I love to see art. & Nose \\
\hline Trial 5 & That was a loud sound. & Paper \\
\hline Trial 6 & The boy won the race. & Square \\
\hline Trial 7 & We need to talk now. & Rat \\
\hline Trial 8 & I read the note. & King \\
\hline Trial 9 & We will host a party. & Tree \\
\hline Trial 10 & The sun will rise. & Chair \\
\hline Trial 11 & Please watch the film. & Rain \\
\hline Trial 12 & I have pain in my arm. & Hat \\
\hline Trial 13 & The car needs gas. & Ring \\
\hline Trial 14 & He is on the main floor. & Leg \\
\hline Trial 15 & March is a nice month. & Train \\
\hline Trial 16 & You should go for a walk. & Clown \\
\hline Trial 17 & That is the truth. & Cup \\
\hline Trial 18 & Do not include the red. & Truck \\
\hline Trial 19 & Tell me a story. & Shell \\
\hline Trial 20 & I will ride a horse today. \\
\hline
\end{tabular}




\begin{tabular}{|l|l|l|}
\hline \multicolumn{2}{|c|}{ Module 5 English } \\
\hline & Sentences & Terminal Word \\
\hline Trial 1 & I will start this term. & Bear \\
\hline Trial 2 & The soda is flat. & Horn \\
\hline Trial 3 & I do not feel pain. & Seed \\
\hline Trial 4 & They won the game. & Ear \\
\hline Trial 5 & She is very fit. & Wave \\
\hline Trial 6 & That is a new desk. & Gate \\
\hline Trial 7 & There is a old score. & Cow \\
\hline Trial 8 & The plant grew. & Tail \\
\hline Trial 9 & He has a goal. & Card \\
\hline Trial 10 & The text is blue. & Swing \\
\hline Trial 11 & Do not tell a lie. & Cap \\
\hline Trial 12 & Put the ball in the hole. & Fence \\
\hline Trial 13 & A pale is for the beach. & Pan \\
\hline Trial 14 & She will raise the bar. & Jet \\
\hline Trial 15 & The floor is dry. & Nail \\
\hline Trial 16 & I will seek more. & Shirt \\
\hline Trial 17 & The fur is soft. & Flag \\
\hline Trial 18 & That was a hard test. & Salt \\
\hline Trial 19 & The grass is green. & Tie \\
\hline Trial 20 & That guy is smart. & Cab \\
\hline Trial 21 & A snake has not feet. & Pen \\
\hline Trial 22 & We should go to the coast. \\
\hline Trial 23 & He was all about honor. & Tent \\
\hline Trial 24 & It is half past noon. & \\
\hline Trial 25 & Cut the hedge. & Wig \\
\hline
\end{tabular}


Appendix H. Sentence and Terminal Word Stimulus for the Listening Span Task in Spanish.

\begin{tabular}{|l|l|l|}
\hline \multicolumn{2}{|c|}{ Module 1 Spanish } \\
\hline & Sentences & Terminal Word \\
\hline Trial 1 & Milibroesrojo. & Pelo \\
\hline Trial 2 & Dame mas comida. & Gato \\
\hline Trial 3 & TengoEscuela Hoy. & Hombre \\
\hline Trial 4 & El pastel esrico. & Balon \\
\hline Trial 5 & El sol escaliente. & Javon \\
\hline
\end{tabular}

\begin{tabular}{|l|l|l|}
\hline \multicolumn{2}{|c|}{ Module 2 Spanish } \\
\hline & Sentences & Terminal Word \\
\hline Trial 1 & El pezesgrande. & Perro \\
\hline Trial 2 & Tengo mucho calor. & Bolsa \\
\hline Trial 3 & Hieloesfrio. & Puerta \\
\hline Trial 4 & El sofa esblanco. & Rana \\
\hline Trial 5 & Hay sieteglobos. & Llave \\
\hline Trial 6 & Duermo en unacama. & Huevo \\
\hline Trial 7 & Quieroir a la playa. & Mesa \\
\hline Trial 8 & No tengodinero. & Caja \\
\hline Trial 9 & Tedio un reloj. & Bicho \\
\hline Trial 10 & Teveomanana. & Red \\
\hline
\end{tabular}




\begin{tabular}{|l|l|l|}
\hline \multicolumn{2}{|c|}{ Module 3 Spanish } \\
\hline & Sentences & Terminal Word \\
\hline Trial 1 & La callees negro. & Leon \\
\hline Trial 2 & Ella eslinda. & Pluma \\
\hline Trial 3 & Coje la bola. & Flor \\
\hline Trial 4 & Voy al parque. & Vela \\
\hline Trial 5 & Compre un vestido. & Dedo \\
\hline Trial 6 & Mananaesjueves. & Sosten \\
\hline Trial 7 & No puedocantar. & Toro \\
\hline Trial 8 & El maresazul. & Soda \\
\hline Trial 9 & Dame unahoja de papel. & Cabra \\
\hline Trial 10 & Tengoqueir al banco. & Rama \\
\hline Trial 11 & En unahoraviene el bus. & Cerdo \\
\hline Trial 12 & Pon la media en tu pie. & Pato \\
\hline Trial 13 & Hay papel en la bolsa. & Avion \\
\hline Trial 14 & Vete a la tienda. & Nido \\
\hline Trial 15 & El carroesrojo. & Mono \\
\hline
\end{tabular}




\begin{tabular}{|l|l|l|}
\hline \multicolumn{3}{|c|}{ Module 4 Spanish } \\
\hline & Sentences & Terminal Word \\
\hline Trial 1 & Fui al mercado hoy. & Pala \\
\hline Trial 2 & Yopiensoquesi. & Cuello \\
\hline Trial 3 & El telefonoestasonando. & Negro \\
\hline Trial 4 & Voy a montar el caballo. & Sofa \\
\hline Trial 5 & Subelasmanos pa arriba. & Ojo \\
\hline Trial 6 & Unavacaesblanco y negro. & Rey \\
\hline Trial 7 & El inviernoesfrio. & Papel \\
\hline Trial 8 & La plumatienetinta. & Rata \\
\hline Trial 9 & Ella va a regresar. & Lluvia \\
\hline Trial 10 & Me gustanlasfresas. & Goma \\
\hline Trial 11 & Vamos al teatro. & Arbol \\
\hline Trial 12 & Escucha la musica. & Cruz \\
\hline Trial 13 & Vamos a jugar. & Sello \\
\hline Trial 14 & Vas a llover. & Banco \\
\hline Trial 15 & Abril es el proximomes. & Sol \\
\hline Trial 16 & Esmuytarde. & Reina \\
\hline Trial 17 & Eselamparaestaapagado. & Nube \\
\hline Trial 18 & Ponte sugorra. & Camion \\
\hline Trial 19 & Yaestoy en camino. & Piene \\
\hline Trial 20 & Estoyleyendo un libro. & Pastel \\
\hline
\end{tabular}




\begin{tabular}{|l|l|l|}
\hline \multicolumn{3}{|c|}{ Module 5 Spanish } \\
\hline & Sentences & Terminal Word \\
\hline Trial 1 & Dame tumano. & Rosa \\
\hline Trial 2 & Es un vaquero. & Casa \\
\hline Trial 3 & No tengo dolor. & Ola \\
\hline Trial 4 & Estalloviendoafuera. & Oso \\
\hline Trial 5 & Voy a hacerejercicio. & Mano \\
\hline Trial 6 & Me sientomuycansada. & Salto \\
\hline Trial 7 & Voy a caminar al perro. & Palma \\
\hline Trial 8 & Su madreesagradable. & Pan \\
\hline Trial 9 & El tiene un tigre. & Bus \\
\hline Trial 10 & Manda un mensaje. & Cola \\
\hline Trial 11 & Voy a unavisita con el doctor. & Dado \\
\hline Trial 12 & Sécómojugar al golf. & Torta \\
\hline Trial 13 & Son peces en el mar. & Globo \\
\hline Trial 14 & Las estrellasestánfuera. & Clavo \\
\hline Trial 15 & Voy a limpiar el piso. & Cerca \\
\hline Trial 16 & Estiempo de trabajo. & Cono \\
\hline Trial 17 & El conejoes suave. & Reloj \\
\hline Trial 18 & Tengo un examenmañana. & Cheque \\
\hline Trial 19 & Minombrees Maria. & Taxi \\
\hline Trial 20 & Mañanaes el juego. & Cubo \\
\hline Trial 21 & No voyaextrañaresaclase. & Rata \\
\hline Trial 22 & Tiene dos hermanos. & Lengua \\
\hline Trial 23 & La niñaestá en el ejército. & Regla \\
\hline Trial 24 & Ponte unachaqueta. & \\
\hline Trial 25 & Necesitamosunasvacaciones. & Olla \\
\hline
\end{tabular}

